\title{
Química mineral e condições de cristalização de granitos intrudidos ao lon- go da Zona de Cisalhamento Remígio - Pocinhos, NE do Brasil: Plúton Pilõe- zinhos
}

\author{
Jefferson Valdemiro de LIMA¹, Ignez de Pinho GUIMARÃES², Lucilene SANTOS ${ }^{1}$, Douglas José \\ FARIAS $^{1} \&$ José Victor ANTUNES ${ }^{1}$
}

1 Programa de Pós-Graduação em Geociências, Universidade Federal de Pernambuco. Av. da Arquitetura, s/n, 3ํandar, CEP 50.740-550, Recife, Brasil (jefferson1901@hotmail.com, lucilene.santo01@gmail.com, douglasjsfarias@yahoo.com.br, zehantunes@gmail.com.

2 Departamento de Geologia, Universidade Federal de Pernambuco. Av. da Arquitetura, s/n, 5o andar, CEP 50.740-550, Recife, Brasil (Ignez@ufpe.br).

Recebido em 05/2016. Aceito para publicação em 12/2016.

Versão online publicada em 08/05/2017 (www.pesquisasemgeociencias.ufrgs.br)

\begin{abstract}
Resumo - O Plúton Pilõezinhos (PP) constitui uma intrusão alongada com 100 km² na porção NE do Domínio Central da Província Borborema. Compreende monzogranitos e sienogranitos, subdivididos em duas fácies petrográficas distintas. O PP está posicionado no encontro entre as zonas de cisalhamento: destral Remígio - Pocinhos (ZCRP), e sinistral Matinhas. Este trabalho tem como objetivo principal a caracterização das condições de cristalização dos granitos do PP. A mineralogia principal, caracterizada a partir da petrografia e análises por Microssonda Eletrônica, é composta por: quartzo; feldspatos alcalinos, representado por cristais de microclínio e pertitas; plagioclásio, variando de oligoclásio a andesina; biotita rica na molécula de siderofilita; e anfibólios variando de hastingsita a Fe-tchermakita. A mineralogia acessória compreende titanita, zircão, apatita, óxidos, e allanita, mineral que detém grande quantidade de ETR. As condições termobarométricas nas quais esses granitos cristalizaram, obtidas a partir dos dados de química mineral, são: temperatura variando de 745 a $1003{ }^{\circ} \mathrm{C}$, definida a partir do geotermômetro anfibólio - plagioclásio e geotermômetro do Zr, e pressão de 4,28 a 5,95 Kbar (geobarômetro $\mathrm{Al}^{\mathrm{T}}$ em hornblendas). Minerais máficos ricos em ferro e a presença de ilmenita primária sugerem cristalização sob condições de baixa $\mathrm{fO}_{2}$ (abaixo do tampão FMQ). Reequilíbrio em estágio subsolidus, a partir da atuação de fluidos tardios com temperaturas variando de 505 a $566^{\circ} \mathrm{C}$ é sugerido pela presença de sericita, mirmequita e clorita. As feições mineralógicas, químicas e estruturais sugerem que esses granitos representam magmatismo tipo- $\mathrm{A}_{2,}$ que evoluiu por cristalização fracionada.

Palavras-chave: granitos tipo- $A_{2}$, Província Borborema, magmatismo extensional, termobarometria.
\end{abstract}

\begin{abstract}
MiNERAL CHEMISTRY AND CRYSTALLIZATION CONDITIONS OF GRANITES EMPLACED ALONG the Remígio-Pocinhos Shear Zone, NE Brazil: Pilõezinhos Pluton. The Pilõezinhos Pluton (PP). comprises a $\sim 100 \mathrm{~km}^{2}$-elongated intrusion in the NE part of the Transversal Domain of the Borborema Province. It is composed of monzogranites and syenogranites, subdivided into two distinct petrographic facies. The PP intrudes the boundary between the dextral Remigio - Pocinhos and sinistral Matinhas shear zones. The main objective of this work is to characterize the conditions of crystallization from the PP granites. The main mineralogy was characterized by petrography and Electron Microprobe mineral chemistry analysis. It consists of quartz; alkali feldspars (microcline and pertite); plagioclase, ranging from oligoclase to andesine; siderophillite-rich biotite; and amphibole, with composition ranging from hastingsite to Fe-tschermakite. The accessory mineralogy comprises titanite, zircon, apatite, oxides, dominantly ilmenite, and allanite grains holding large amount of REE. The mineral chemistry defined that the magma crystallization occurred at temperature ranging from 745 to $1003^{\circ} \mathrm{C}$, defined from the amphibole - plagioclase geothermometer and $\mathrm{Zr}$ geothermometer, and pressure from 4.28-5.98 kbar (geobarometer of $\mathrm{Al}^{\mathrm{T}}$ in hornblendas). Iron-rich mafic mineralogy and the presence of primary ilmenite suggest crystallization under low $\mathrm{fO}_{2}$ conditions, below the FMQ buffer. Rebalancing in subsolidus conditions occurs due to the action of late fluids, with temperatures ranging from 505 to $566^{\circ} \mathrm{C}$, is suggested by the presence of sericite, chlorite and myrmekite. The mineralogical, chemical and structural features suggest that the PP granites represent $\mathrm{A}_{2}$-type magmatism, which evolved by fractional crystallization.
\end{abstract}

Keywords: $A_{2}$-type granites, Borborema Province, extensional magmatism, thermobarometry. 


\section{Introdução}

A Província Borborema (Almeida et al., 1977) consiste numa região de $450.000 \mathrm{~km}^{2}$, situada a norte do Cráton São Francisco, delimitada a leste e norte pelo Oceano Atlântico, e a oeste pela Bacia do Parnaíba, nordeste do Brasil. Van Schmus et al. (2008) dividiram a Província Borborema nos domínios: Médio Coreaú, Ceará, Rio Grande do Norte, Transversal e Sul. A área estudada está localizada na porção nordeste do Domínio Transversal.

A estruturação atual da Província Borborema (Fig. 1A) é resultante da orogênese Brasiliana (= Pan-Africano; 640-580 Ma - Van Schmus et al., 2008). A Província Borborema é constituída por quatro unidades maiores: Embasamento Paleoproterozoico, composto por complexos gnáissicos migmatíticos formados durante o Riaciano $(2,2 \mathrm{Ga}$ - 1,8 Ga), contendo pequenos núcleos arqueanos com idades U-Pb (zircão) entre 3,4 e 3,1 Ga (Hackspacher et al., 1991; Brito Neves, 1995; Brito Neves et al., 1995; Van Schmus et al., 1995; Dantas et al., 1998); faixas de dobramentos neoproterozoicos (Toniana e Ediacarana), constituídas de sequências supracrustais deformadas e metamorfizadas que circundam os complexos gnáissicos; granitos neoproterozoicos (Toniano e Ediacarano); e extensas zonas de cisalhamento de caráter transcorrente, com direção dominantemente NE-SW e E-W.

Uma das principais feições associada à Orogênese Brasiliana na Província Borborema é a presença de um intenso magmatismo granítico associado em grande parte a um sistema de zonas de cisalhamento transcorrentes destrais, com direção E-W, e sinistrais, com direção NE-SW (Vauchez \& Egydio-Silva, 1992; Guimarães \& Da Silva Filho, 1998; Ferreira et al., 1998; Neves \& Mariano, 1999; Neves et al., 2000; Silva \& Mariano, 2000), incluindo a dos principais lineamentos da província (Pernambuco e Patos), e suas ramificações. 0 metamorfismo da área é caracterizado sob condições de fácies anfibolito alto.

Essas inúmeras manifestações graníticas distribuídas ao longo da Província Borborema foram inicialmente agrupadas por Almeida et al. (1967) em granitos dos tipos: Conceição (granodioritos e tonalitos); Itaporanga (granodioritos extremamente porfiríticos); Itapetim (biotita granitos tardi orogênicos); Catingueira (granitos peralcalinos, quartzo sienitos e sienitos).

Sial (1986) caracterizou geoquimicamente a granitogênese na Faixa Piancó Alto Brígida (Cinturão Cachoeirinha-Salgueiro), no Domínio Transversal, e os correlacionou aos granitos descritos por Almeida et al. (1967) em: 1) cálcio-alcalinos
(Tipo Conceição); 2) cálcio-alcalinos potássicos (Tipo Itaporanga); 3) peralcalinos (Tipo Catingueira); e 4) trondhjemítico (Tipo Serrita).

Ferreira et al. (1998), utilizando afinidades petrogenéticas, geoquímicas, estudos isotópicos e susceptibilidade magnética, dividiram os granitos da porção oeste da Zona Transversal em oito tipos principais: cálcio-alcalino com epídoto magmático (Conceição); cálcio alcalino de alto potássio sem epídoto magmático (Itaporanga); cálcio-alcalino de alto potássio com epídoto (São Rafael); cálcio-alcalinos peraluminosos (Ouro Branco); trondhjemitos (Serrita); peralcalinos (Catingueira) e shoshoníticos; sienitoides metaluminosos de alto potássio (Terra Nova); e sienitoides peralcalinos ultrapotássicos (Triunfo/Baixa Verde).

Guimarães et al. (1998), a partir de dados de composição mineralógica, afinidade geoquímica, natureza das encaixantes e dos possíveis protólitos, dividiram os granitos do Domínio Transversal da Província Borborema em cinco tipos principais, os quais foram posteriormente reagrupados por Guimarães et al. (2004) em quatro tipos: 1) Granitos cálcio-alcalinos com idade de 610-644 Ma; 2) Granitos cálcio-alcalinos de alto-K e shoshonítico com idade U-Pb em zircão de 590 -581 Ma, transicionais entre evento de baixo ângulo e evento de transcorrência; 3) Granitos alcalinos pós-colisionais com idade $\mathrm{U}-\mathrm{Pb}$ de cerca de $570 \mathrm{Ma}$; e 4) Granitóides tipo-A pós-orogênicos associados a magmatismo bimodal subvulcânico com idade entre 540 e $512 \mathrm{Ma}$.

Neste trabalho, apresentamos e discutimos as feições de campo, petrografia e química mineral, a partir das quais foram inferidas as condições de pressão, temperatura e $\mathrm{fO}_{2}$ durante a cristalização dos granitos tipo- $\mathrm{A}_{2}$ (Lima et al., 2015a) do Plúton Pilõezinhos, intrudido ao longo da Zona de Cisalhamento Remígio - Pocinhos (ramo leste da Zona de Cisalhamento Patos), no Domínio Transversal da Província Borborema, contribuindo dessa forma para o conhecimento da granitogênese na Província Borborema e de sua relação com zonas de cisalhamento.

\section{2 Área, materiais e métodos}

\subsection{Contexto geológico do Plúton Pilõezinhos}

O Plúton Pilõezinhos (Fig. 1B) compreende uma intrusão alongada, com direção aproximada ENE-WSW, com $100 \mathrm{~km}^{2}$ de área, limitado ao norte pela zona de cisalhamento com cinemática destral Remígio - Pocinhos (ZCRP), próximo a sua 
terminação com a zona de cisalhamento Matinhas de cinemática sinistral e direção NE-SW. A ZCRP compreende o ramo leste da Zona de Cisalhamen- to Patos, que limita os domínios Transversal e Norte da Província Borborema.

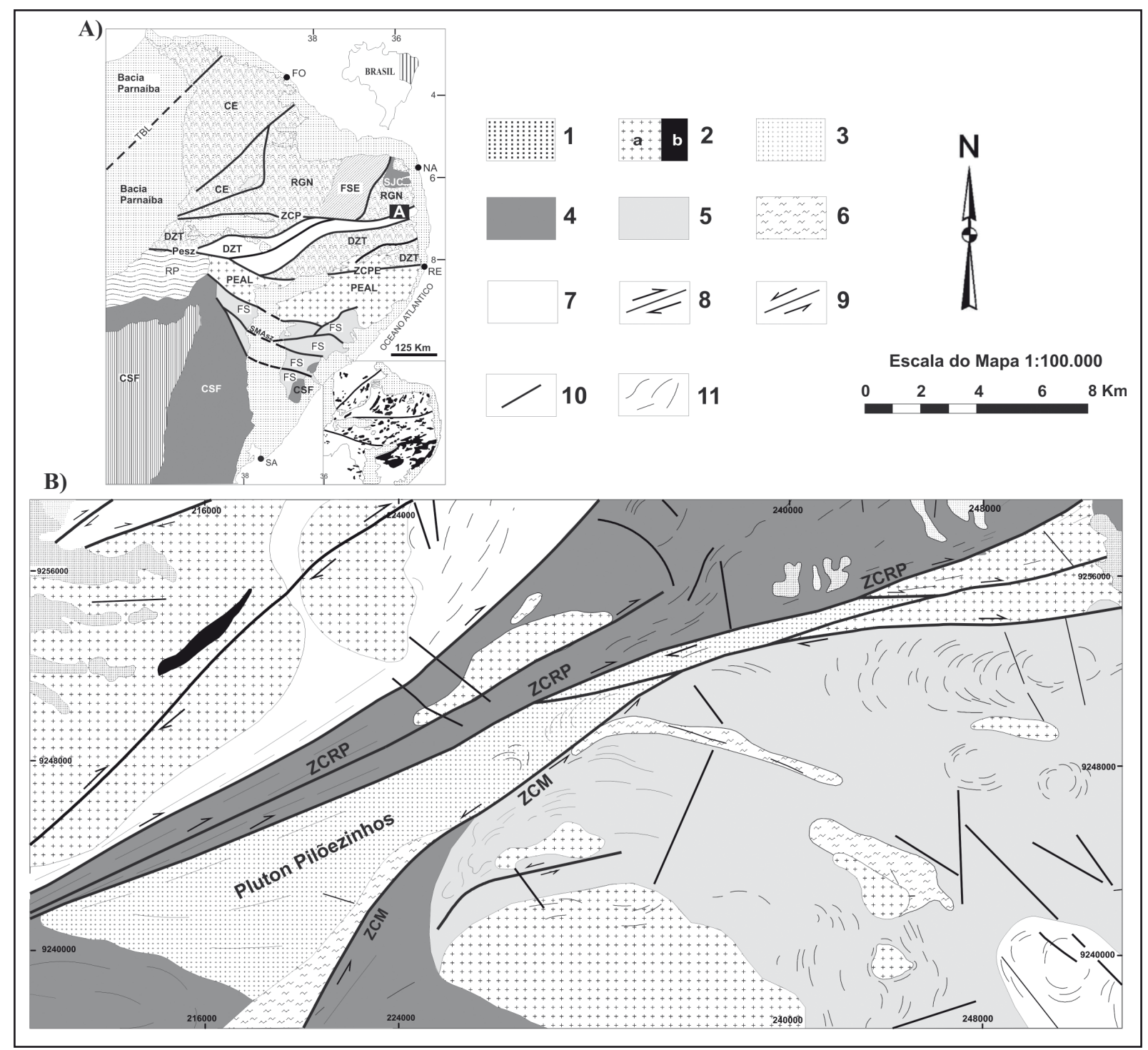

Figura 1. Mapas de localização. A) Grandes domínios e subdomínios da Província Borborema (Van Schmus et al., 2008) CSF= Cráton São Francisco; FS = Faixa Sergipana; FRP = Faixa Riacho do Pontal; PEAL = Subdomínio Pernambuco Alagoas; FSE = Faixa Seridó; SJC = Núcleo arqueano São José do Campestre; CE = Domínio Ceará; RGN = Domínio Rio Grande do Norte; ZCPE = Zona de Cisalhamento Pernambuco; ZCP = Zona de Cisalhamento Patos; A = Área de estudo. ENCARTE - Distribuição dos granitos brasilianos da Província Borborema segundo Silva Filho et al. (2013); B) Mapa geológico simplificado da área estudada, modificado a partir dos mapas das folhas Solânea/SB.25-Y-A-IV (Guimarães et al., 2008) e Guarabira/SB.25-Y-A-V (Guimarães \& Bittar, 2011). 1: Coberturas Fanerozoicas; 2- a: Granitos brasilianos, b: dioritos; 3: Plúton Piloezinhos, 4: Metassedimentos Brasilianos; 5: Metassedimentos de idade não definida (Complexo Sertânia); 6: Ortognaisses Tonianos; 7: Ortognaisses Riacianos; 8: Zonas de Cisalhamento Destrais; 9: Zonas de Cisalhamento Sinistrais; 10: Fraturas; 11: Foto lineamentos; ZCM: Zona de Cisalhamento Matinhas; ZCRP: Zona de Cisalhamento Remígio - Pocinhos.

Figure 1. Location map. A) Major domains and subdomains of the Borborema Province (Van Schmus et al., 2008). CSF= São Francisco craton; FS: Sergipana Belt; FRP = Riacho do Pontal Belt; PEAL = Pernambuco-Alagoas subdomain; FSE = Seridó belt; SJC = São José do Campestre Archean core; CE = Ceará domain; RGN = Rio Grande do Norte domain; ZCPE = Pernambuco Shear Zone; $Z C P=$ Patos Shear Zone; A= Study area. INSERT - Distribution of Brasiliano granites of the Borborema Province after Silva Filho et al. (2013); B) Simplified geological map of the study area, modified from of the Solânea/SB.25-Y-A-IV (Guimarães et al., 2008) $e$ Guarabira/SB.25-Y-A-V (Guimarães \& Bittar, 2011) maps. $1=$ Phanerozoic covers; $2 a=$ Brasiliano granites, $2 b=$ diorites; $3=$ Piloezinhos Pluton; 4= Brasilianos metasediments; 5 = Metasediments of undefined age (Sertânia Complex); $6=$ Tonian orthogneisses; 7 = Rhyacian orthogneisses; $8=$ dextral shear zone; 9 = sinistral shear zone; $10=$ fractures; 11 = lineaments photo; ZCM = Matinhas Shear Zone; ZCRP = Remígio-Pocinhos shear zone. 
0 contexto estrutural gerado pela movimentação sincrônica da ZCRP de direção E-W e cinemática destral, e a Zona de Cisalhamento Matinhas de direção NE-SW e cinemática sinistral, é compatível com o desenvolvimento de um padrão em dominó, possibilitando a abertura do espaço (sítios extensionais) para a colocação dos magmas responsáveis pela cristalização dos granitos do Plúton Pilõezinhos.

A forma alongada do Plúton Pilõezinhos, associada à presença de foliação paralela à direção da ZCRP, sugere tratar de intrusão sintranscorrente, como observado em grande parte dos plútons neoproterozoicos do Domínio Transversal da Província Borborema (Neves et al., 2006).

Os granitos do Plúton Pilõezinhos mostram composição variando de sienogranito a monzogranito, de granulação fina a grossa, e equigranulares a porfiríticos (Fig. 2A) intrudidos em rochas metassedimentares neoproterozóicas e ortognaisses de idade Toniana, localmente milonitizadas e migmatizadas. Nas bordas do plúton observa-se intercalação de granito fino leucocrático com granito de granulação grossa, mostrando contatos sinuosos (Fig. 2B).

Quando próximas à ZCRP, as rochas do Plúton Pilõezinhos apresentam feições típicas de deformação no estado sólido, com o desenvolvimento de foliação s-c evidenciando cinemática destral (Fig. 2C). Foliação magmática é observada nas áreas mais distantes das zonas de cisalhamento e são caracterizadas pela presença de fenocristais suédricos a euédricos de feldspato (Fig. 2D), orientados paralelos à direção da ZCRP, sugerindo intrusão sincrônica a tardi-transcorrente. Localmente, observam-se xenólitos dos metassedimentos das encaixantes.

\subsection{Materiais e métodos}

Para este trabalho, foram utilizadas amostras de rochas e dados estruturais coletados durante etapas de campo. Essas amostras foram posteriormente utilizadas para a confecção de seções delgadas e polidas, no Laboratório de Laminação da Universidade Federal de Pernambuco, para o estudo em detalhe da mineralogia dos granitos através da petrografia, com o auxílio no microscópio óptico de luz refletida e transmitida pertencentes ao departamento de geologia da UFPE. As amostras polidas foram posteriormente metalizadas com carbono em câmara de vácuo e analisadas através da Microssonda Eletrônica (JEOL modelo JXA-8230 com cinco espectrômetros WDS e um EDS) da Universidade de Brasília, onde foi obtida a composição química dos diversos minerais constituintes das rochas. Para a análise de elementos maiores nos silicatos e óxidos, as condições analíticas consistem em voltagem de aceleração de $15 \mathrm{kV}$, corrente de $10 \mathrm{nA}$, e um diâmetro do feixe eletrônico da ordem de $\mu \mathrm{m}$. Em relação as análises de ETR nos minerais acessórios estudados (allanita e titanita), o equipamento foi operado em uma voltagem de aceleração de $20 \mathrm{kV}$ e uma corrente de 20 nA. Os padrões utilizados são vidros sintéticos à base de óxidos de ETR, confeccionados na Universidade de Chicago - EUA. Os dados de WDS para análise de ETR foram corrigidos usando valores empíricos de interferência para ETR, de acordo com as recomendações de Williams (1996).

Em relação às condições termobarométricas, foi utilizado o geobarômetro alumínio total em hornblenda a partir da calibração de Anderson \& Smith (1995) para o cálculo da pressão de cristalização, e o geotermômetro anfibólio - plagioclásio segundo a calibração de Blundy \& Holland (1990) para o cálculo da temperatura, além do geotermômetro de saturação em zircão de Watson \& Harrison (1983) e Watson (1987). Para as condições de $\mathrm{fO}_{2}$ durante a evolução e cristalização dos magmas graníticos, foi utilizada a composição dos minerais máficos como estimativa e a equação proposta por Wones (1989) para a quantificação da mesma.

\section{Resultados}

\subsection{Petrografia}

As proporções modais de quartzo, K-feldspato e plagioclásio, obtidas de forma estimada (método de visada), foram recalculadas para $100 \%$ e em seguida projetadas no diagrama QAPF (Fig. 3), de acordo com a classificação proposta por Strekeisen (1976) - IUGS, com as tendências evolucionais para as séries magmáticas propostas por Lameyre \& Bowden (1982).

Os granitos do Plúton Pilõezinhos foram divididos em duas fácies: fácies 1 - sienogranito a monzogranito grosso porfirítico, contendo raros enclaves dioríticos e xenólitos das encaixantes; e fácies 2 - monzogranitos equigranulares de granulação fina.

Ao microscópio, ambas as fácies do Plúton Pilõezinhos mostraram composição mineralógica semelhante, divergindo apenas na granulação e porcentagem mineral. Os granitos estudados apresentam quartzo (25-35\% em volume), K-feldspato (35-50\% vol.), plagioclásio (15-40\% vol.), biotita (5-15\% vol.) e anfibólio (5-10\% vol.), como 

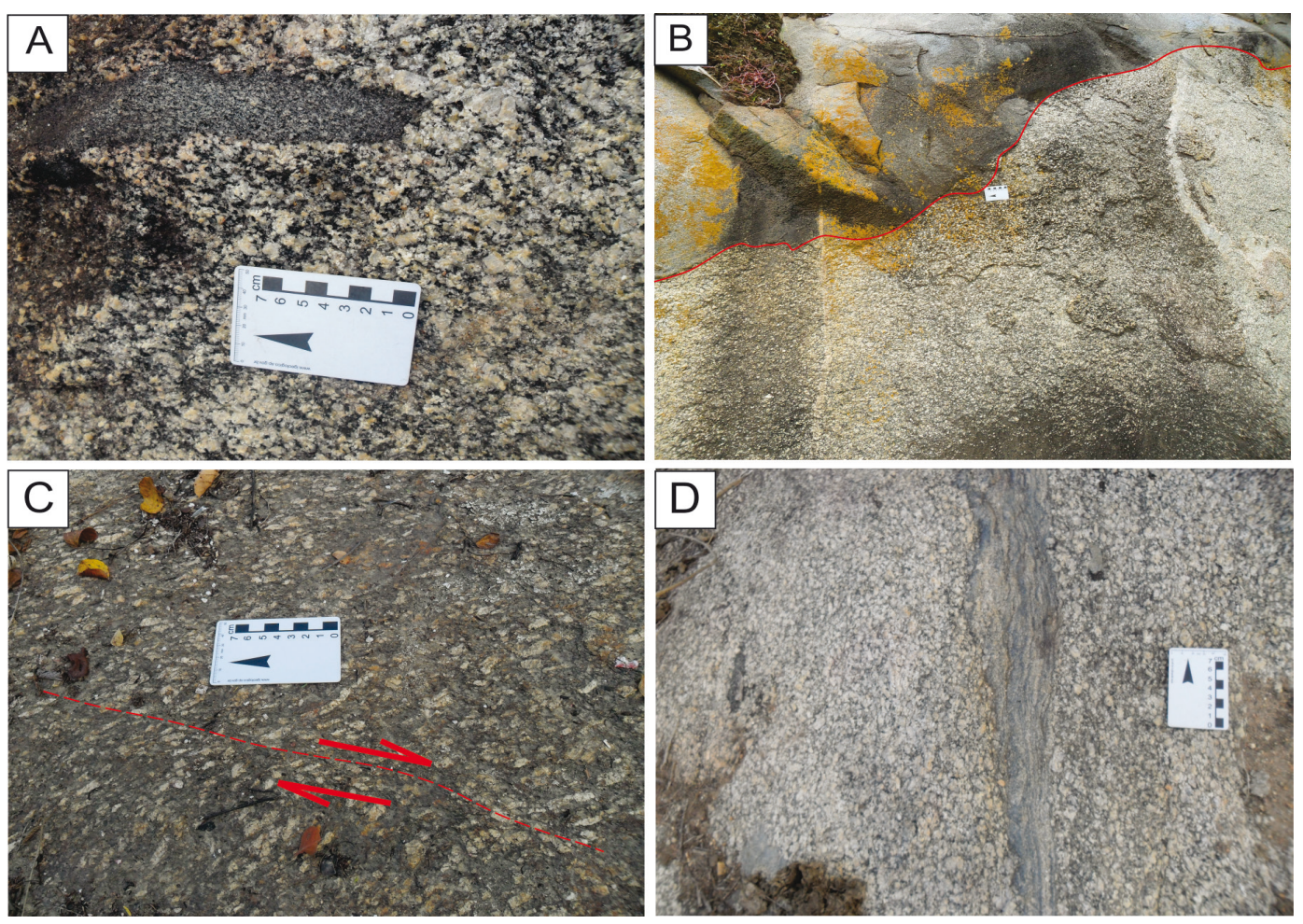

Figura 2. Aspectos de campo do Plúton Pilõezinhos. A) Sienogranito porfirítico contendo enclave diorítico; B) Granito de granulação grossa, porfirítico, mostrando contato sinuoso com granito de granulação fina; C) Granito porfirítico cisalhado com banda de cisalhamento indicando cinemática destral; D) Foliação magmática definida pelo alinhamento dos fenocristais euédricos a subédricos de K-feldspatos e plagioclásio.

Figure 2. Field aspects of Pilõezinhos Pluton. A) Porphyritic syenogranite enclosing dioritic enclave; B) Coarse-grained granitic facies showing sinuous contact with the fine-grained granitic facies; $C$ ) Shear band indicating dextral kinematics in the porphyritic granitic facies; D) Magmatic foliation defined by the alignment of euhedral to subhedral K-feldspars and plagioclase phenocrysts.

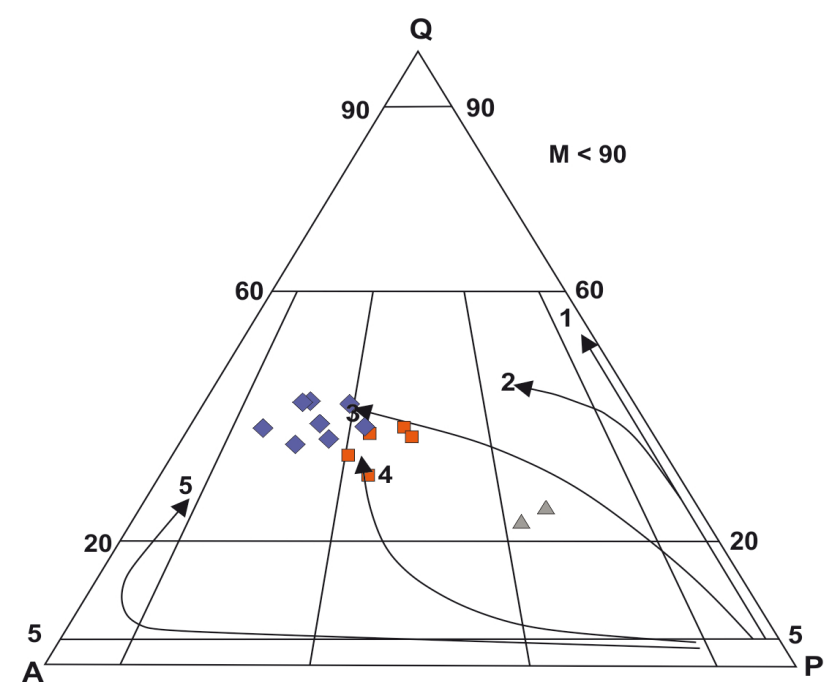

\section{LEGENDA}

Fácies 1 - Sienogranito a monzogranito porfirítico de granulação grossa

- Fácies 2 - Monzogranito equigranular de granulação fina

$\triangle$ Enclave máfico

Figura 3. Composição modal dos granitos estudados projetadas no diagrama Q-A-P para rochas plutônicas (Streckeisen, 1976), com os trends de Lameyre \& Bowden (1982): 1 - toleiítico; 2 - tonalítico ou trondhjemítico cálcio-alcalino; 3 - granodiorítico cálcio-alcalino; 4 - monzonítico ou shoshonítico sub-alcalino; 5 - alcalino e peralcalino.

Figura 3. Modal composition of the studied granites projected in the QAP diagram for plutonic rocks (Streckeisen, 1976), with the trends after Lameyre \& Bowden (1982): 1 - tholeiitic; 2 - tonalitic or calcium-alkali trondhjemítico; 3 - calc-alkaline granodiorite; 4 - monzonitic or subalkaline shoshonitic; 5 - alkaline and peralkaline. 
minerais principais, e titanita (3-5\% vol.), allanita (2-3\% vol.), apatita (1\% vol.), zircão (1\% vol.) e minerais opacos (1\% vol.) como minerais acessórios. 0 quartzo ocorre como cristais anédricos, às vezes recristalizados e/ou como agregados de subgrãos, geralmente exibindo extinção ondulante. Localmente, foi observado quartzo exibindo padrão de extinção em "tabuleiro-de-xadrez" (chessboard patterns) (Fig. 4A), feição típica de deformação em alta temperatura no estado sólido (Kruhl, 1996). Os feldspatos alcalinos, microclina e pertita, ocorrem como fenocristais subédricos e, como cristais anédricos constituindo a matriz da rocha. Os plagioclásios são subédricos e localmente, apresentam zoneamento ígneo preservado (Fig. 4B). Alguns cristais se apresentam fraturados e com fraturas preenchidas por quartzo e felds- pato (fraturas submagmáticas). Frequentemente, os fenocristais de plagioclásio mostram núcleos alterados por processos de sericitização e saussuritização. Alguns fenocristais de feldspato alcalino mostram bordos corroídos por mirmequita (Fig. 4C), possivelmente resultantes da percolação de fluidos tardios associados à deformação (Vernon, 1991). A biotita (Fig. 4D) é a fase máfica dominante e ocorre como palhetas subédricas, apresentando pleocroísmo variando de amarelo a marrom escuro. Localmente ocorre preenchendo espaços entre minerais (biotitas instersticiais). As palhetas de biotitas se mostram, localmente, com ondulações, e alteradas para a clorita (Fig. 4D). Frequentemente, apresentam inclusões de titanita, zircão, allanita e minerais opacos.
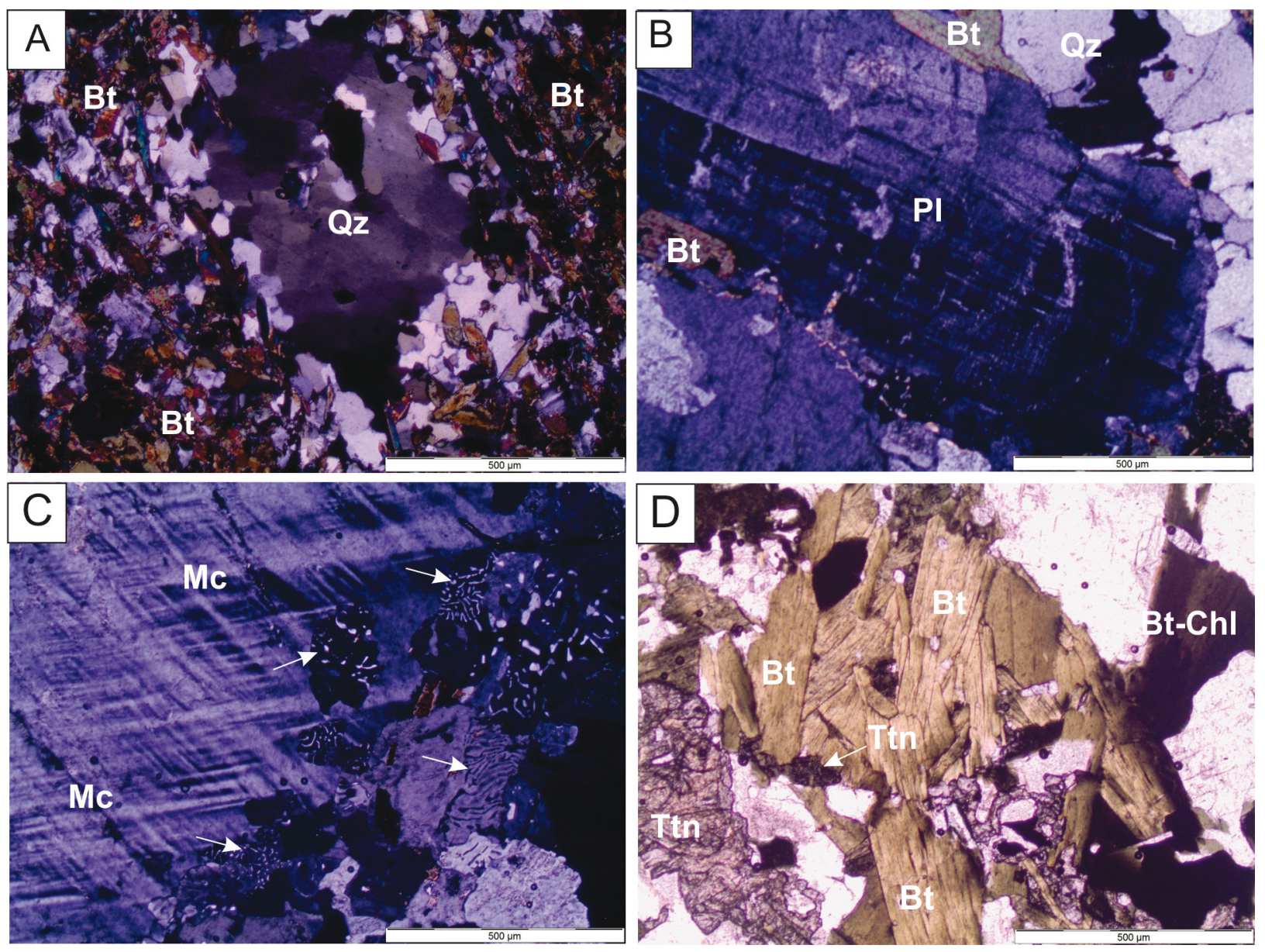

Figura 4. Aspectos petrográficos dos granitos estudados. A) Fotomicrografia exibindo microtextura do tipo chessboard em cristal de quartzo (qtz); B) Zoneamento ígneo preservado em fenocristal de plagioclásio (Pl); C) Intercrescimento mirmequítico (seta branca) nos limites entre fenocristal de microclínio pertítico (Mc) e quartzo; D) Fotomicrografia mostrando placas de biotitas (Bt), biotitas cloritizadas (Bt-Chl) e titanita (Ttn).

Figure 4. Petrographic aspects of the studied granites. A) Photomicrograph showing microtexture chessboard type in quartz crystal (qtz); B) Igneous zoning preserved in plagioclase phenocrysts (PI); C) Mirmekitic intergrowth (white arrow) at the boundaries between phenocrystal of pertitic microcline (Mc) and quartz; D) Photomicrograph showing biotite plate (Bt), chloritized biotites (Bt-Chl) and titanite (Ttn). 
O anfibólio ocorre como cristais subédricos a anédricos, apresenta pleocroísmo caracterizado pela variação de tonalidade entre o amarelo e o verde azulado (Fig. 5A) e, localmente, mostram alteração para clorita. A titanita é o principal mineral acessório encontrado nesses granitos; ocorre como dois tipos texturais diferentes: I) cristais euédricos a subédricos de cor marrom, frequentemente inclusos em biotita e anfibólio, sendo interpretado como titanita primária; e II) cristais anédricos, formando, frequentemente, agregado com forma de coroa em volta de minerais opacos (Fig. 5A), sendo interpretados como titanitas tardi-magmáticas, em grande parte, produto de alteração dos minerais opacos. A allanita ocorre como cristais euédricos a subédricos de coloração amarela ala- ranjada, mostrando frequentemente zoneamento (Fig. 5B). Localmente, se mostram deformadas, possivelmente, por processos de metamictização. Os minerais opacos ocorrem como cristais euédricos a subédricos sendo principalmente ilmenita (Figs. 5C e 5D) identificada ao microscópio de luz refletida pela cor cinza levemente rosa nas bordas, apresentando discreto pleocroísmo e forte anisotropia, características estas distintas das observadas em magnetita. Localmente, ilmenita ocorre como cristais euédricos a subédricos circundados por cristais de titanita ou inclusos em outras fases minerais. A magnetita apresenta-se como pequenos cristais anédricos e em percentagem modal bem menor que a ilmenita, constituindo possivelmente uma fase secundária.
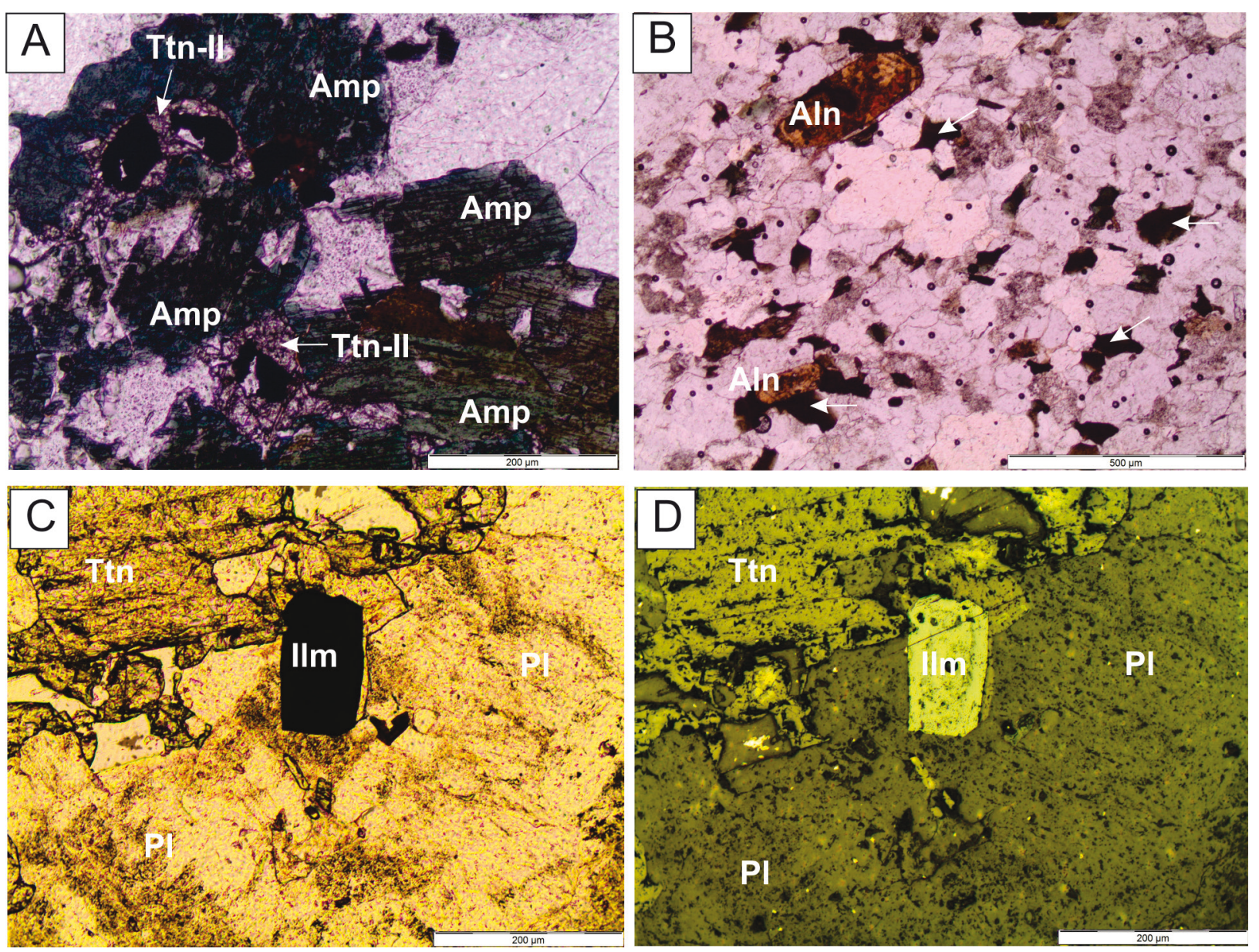

Figura 5. Aspectos petrográficos dos granitos estudados. A) Fotomicrografia exibindo cristais deformados de anfibólio (Amp) em contato com minerais opacos circundado por anel de titanita (Ttn); B) Cristais euédricos de allanita (Aln) zonados, e anfibólio cloritizado (Seta branca); C) Cristal euédrico de ilmenita (Ilm) em contato com titanita e plagioclásio (Pl); D) Cristal euédrico de ilmenita (Ilm) exibido por microscopia de luz refletida.

Figure 5. Petrographic aspects of studied granites. A) Photomicrography showing deformed crystals of amphibole (Amp) in contact with opaque minerals surrounded by titanite ring (Ttn); B) Euhedral allanite crystals (Aln) exhibiting zoning, and chloritized amphiboles (white arrow); C) Euhedral ilmenite crystal (Ilm) in contact with titanite and plagioclase (Pl); D) Euhedral ilmenite crystals (Ilm) reflected light microscopy. 
Petrograficamente, os enclaves do Plúton Pilõezinhos são compostos de cristais anédricos de quartzo exibindo leve extinção ondulante, pertita, em pequenas proporções, fenocristais subédricos a anédricos de plagioclásio pouco alterados, exibindo a típica geminação polissintética e localmente mostrando zoneamento ígneo. Biotita é o principal mineral máfico presente e ocorre como lamelas deformadas com pleocroísmo variando de amarelo a laranja e exibindo, localmente, alteração para clorita. Anfibólio ocorre em pequena quantidade. Os minerais acessórios são representados por cristais euédricos de apatita, localmente aciculares, inclusos em outras fases minerais posteriores e cristais euédricos de zircão, geralmente inclusos em biotita.

\subsection{Química Mineral}

\subsubsection{Biotita}

Foram realizadas análises em 25 cristais de biotita e os dados representativos são mostrados na tabela 1. No diagrama de Nachit et al. (2005), os cristais de biotita analisados dos granitos e enclaves, se projetam essencialmente no campo biotitas primária (Fig. 6A), o que corrobora o seu aspecto microtextural primário observado no estudo petrográfico, com algumas poucas análises na transição para o campo de biotita primária reequilibrada, que pode estar associado a um reequilíbrio em estágio magmático tardio. Os cristais de biotita dos granitos estudados apresentam elevado con-
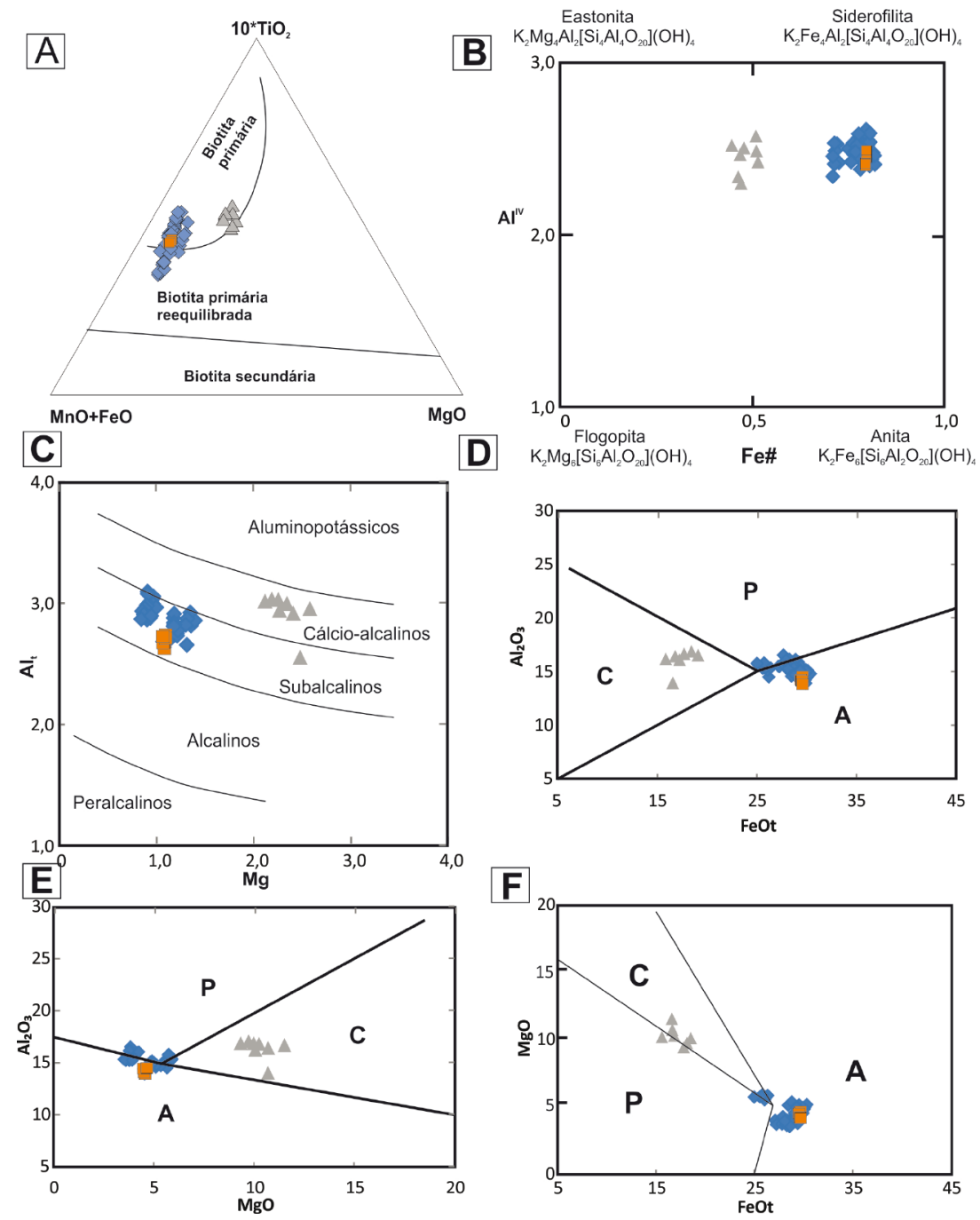

Figura 6. Diagramas químicos para a classificação de cristais de biotita. A) Diagrama ternário MgO x 10 TiO x MnO + FeO (Nachit et al., 1985) para os cristais de biotita estudados; B) Diagrama Fe\# x Alvi ;) Diagrama Mg x Alt de Nachit et al. (1985); D-E-F) Digramas de Abdel-Rahman (1994). Símbolos como na figura 3. A= alcalino anorogênico; $\mathrm{C}=$ cálcio-alcalino; $\mathrm{P}=$ peraluminoso. Figure 6. Chemical diagrams for the classification of biotite crystals. A) MgO x $10 \mathrm{TiO} \times \mathrm{MnO}+\mathrm{FeO}$ ternary diagram (Nachit et al., 1985) for the studied biotites crystals; B) Fe x Al diagram; C) Mg x Al diagram after Nachit et al. (1985); D), E), F) - Diagrams after Abdel-Rahman (1994). Symbols as Figure 3. A: alkaline anorogenic; C: calc-alkaline; P: peraluminous. 
teúdo de ferro (Fig. 6B), com valores de Fe\# [FeO/ ( $\mathrm{FeO}+\mathrm{MgO})]$ variando de 0,72 a 0,82 , e os cristais dos enclaves máficos mostram teores de magnésio mais elevados, com razões [ $\mathrm{FeO} /(\mathrm{FeO}+\mathrm{MgO})]$ variando de 0,45 a 0,51 . Os cristais de biotita dos granitos e enclaves estudados mostram composição semelhante às de rochas da série subalcalina e cálcio-alcalina, respectivamente (Fig. 6C). Os teores de ferro nos cristais de biotitas sugerem condições redutoras durante a evolução do magma. Os teores de $\mathrm{FeO}_{\mathrm{t}^{\prime}} \mathrm{MgO}$ e $\mathrm{Al}_{2} \mathrm{O}_{3}$ observados nos cristais de biotitas dos granitos e enclaves, são semelhantes às biotitas pertencentes, respectivamente, a granitos alcalinos anorogênicos e cálcio-alcalinos
(Abdel Rahman, 1994) (Figs. 6D, 6E e 6F); porém, algumas poucas amostras dos granitos evidenciam uma certa tendência peraluminosa, ainda que em pequena escala.

\subsubsection{Anfibólio}

Foram realizadas análises em 20 cristais de anfibólio e os dados representativos são mostrados na tabela 2. Os cristais de anfibólio do Plúton Pilõezinhos mostram composição típica de anfibólios magmáticos (Czamanske \& Wones, 1973) (Fig. 7A) e, assim como os cristais de biotita, apresentam elevado conteúdo de ferro (Fe\# variando de

Tabela 1. Composição química e proporções catiônicas $(\mathrm{O}=24)$ - Biotita/Amostras representativas.

Table 1. Chemistry composition and cationic proportions $(\mathrm{O}=24)$ - Biotite/Representative samples.

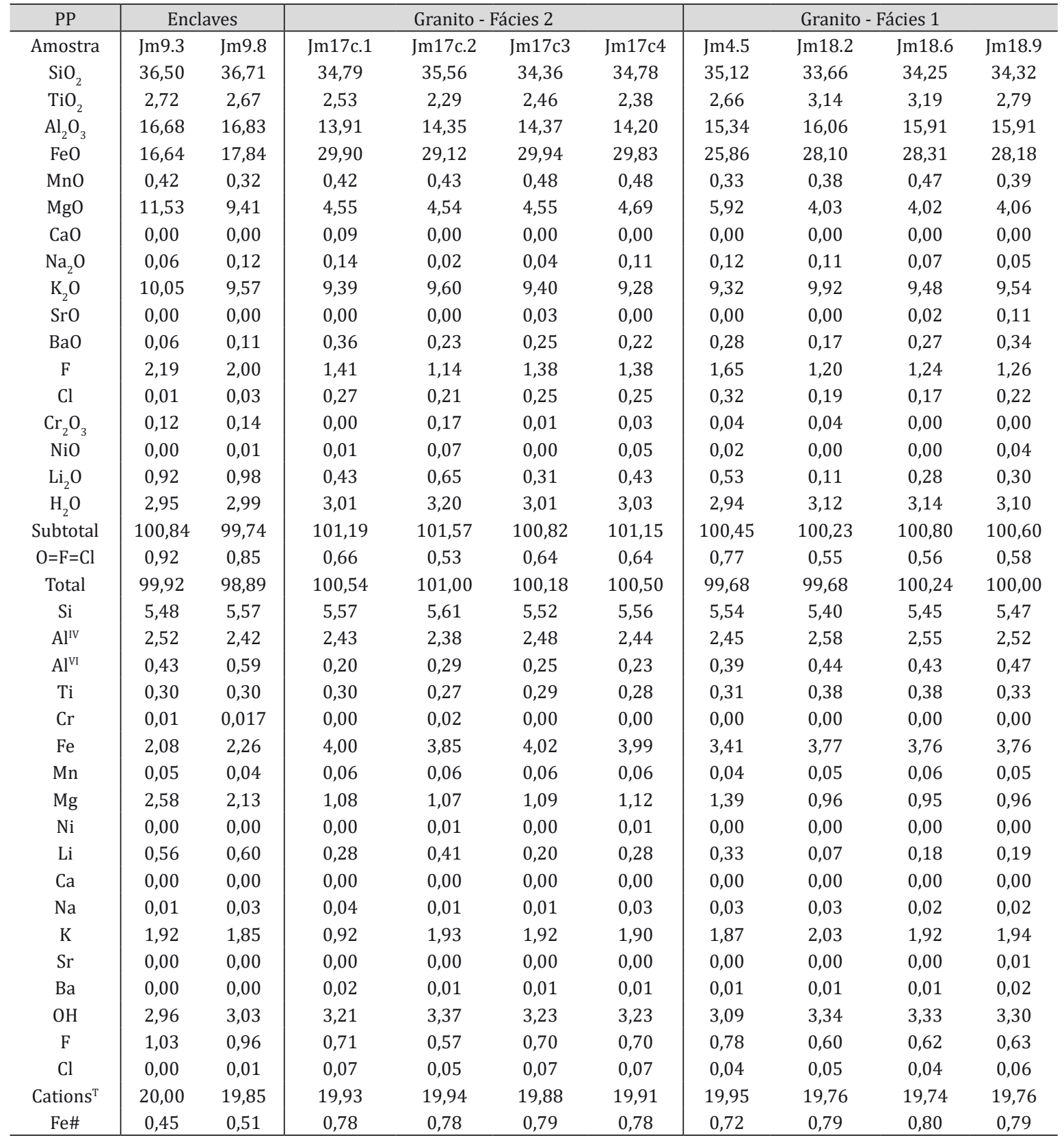


$0,80$ a 0,89$)$, sendo classificados de acordo com Leake et al. (1997) como hastingsita e Fe-tchermakita (Figs. 7B e 7C). Esses valores do Fe\# observados nos cristais de anfibólio são semelhantes aos observados na química de rocha total (Lima et al., 2015a), e evidenciam cristalização em condições de baixa $\mathrm{fO}_{2}$ (Fig. 7D).
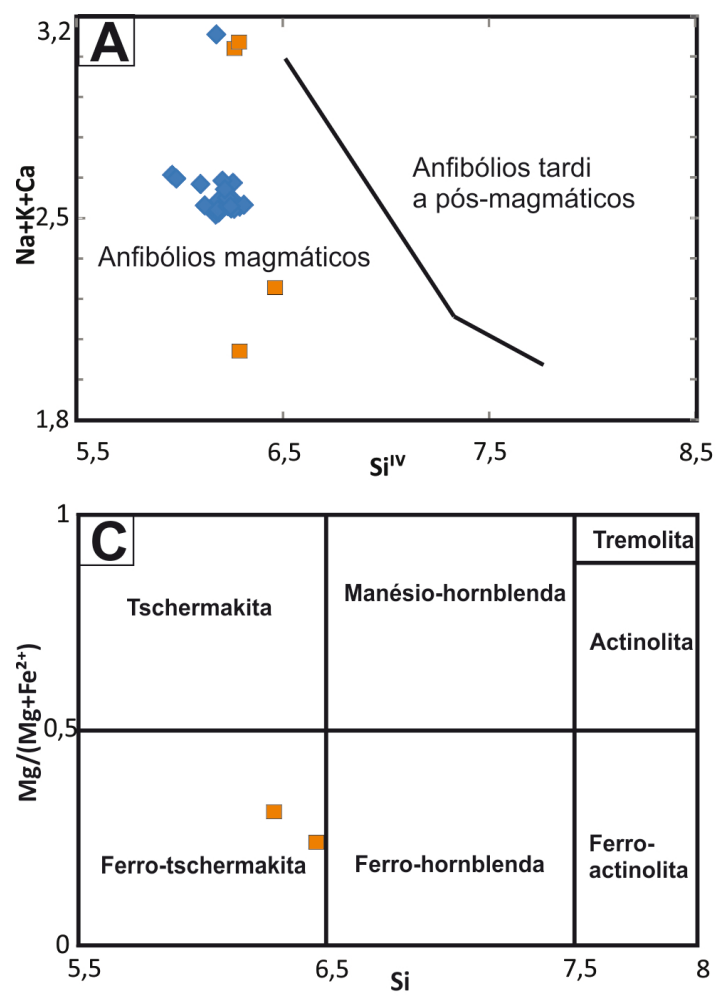

\subsubsection{Cloritas}

Para a clorita foram realizadas análises em 7 cristais (Tab. 3). Os cristais de clorita analisados são caracterizados por elevados teores de ferro (cloritas não oxidadas), com [Fe/Fe+Mg] variando entre 0,77 e 0,80, sendo classificadas, de acordo com Bailey (1980), como chamosita.
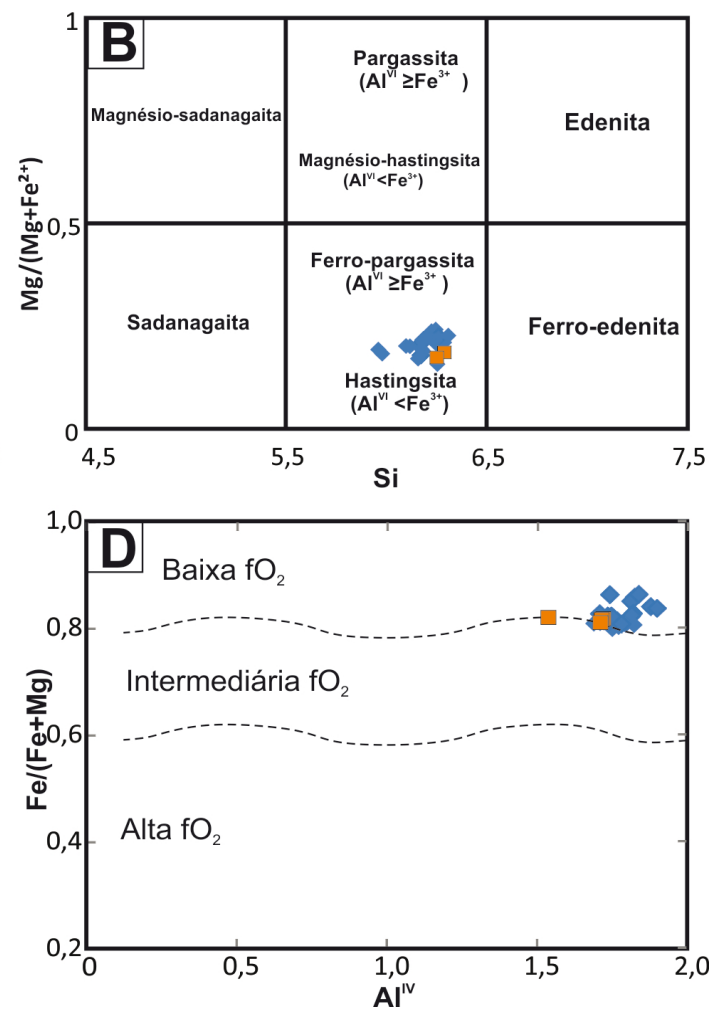

Figura 7. Diagramas químicos para classificação de anfibólios. A) Diagrama $\mathrm{Si}^{\mathrm{IV}} \mathrm{x}(\mathrm{Na}+\mathrm{K}+\mathrm{Ca})$ com os campos de Czamanske \& Wones (1973); B) e C) Diagramas para classificação de cristais de anfibólios de Leake et al. (1997); D) Diagrama Al ${ }^{\mathrm{IV}} \mathrm{x}$ Fe/ ( $\mathrm{Fe}+\mathrm{Mg})$, com os campos de $\mathrm{fO}_{2}$ segundo Anderson \& Smith (1995). Símbolos como na figura 3.

Figure 7. Chemical diagrams of amphibole classification. A) $\mathrm{Si}^{I V} \mathrm{x}(\mathrm{Na}+\mathrm{K}+\mathrm{Ca})$ diagram, with fields after (Czamanske e Wones, 1973); B) and C) Diagram for the classification of amphiboles cristals according to Leake et al. (1997); D) $\mathrm{Al}{ }^{\mathrm{V}} \mathrm{x} \mathrm{Fe} /(\mathrm{Fe}+\mathrm{Mg}) \mathrm{dia}-$ gram with $\mathrm{fO}_{2}$ fields after Anderson \& Smith (1995). Symbols as figure 3.

A temperatura de formação da clorita nos granitos estudados, calculada a partir da equação proposta por Jowett (1991), forneceu resultados de 505 e $566^{\circ}$. Estes dados podem ser interpretados como sendo a estimativa da temperatura na qual ocorreram alterações hidrotermais, no estágio subsolidus, que geraram a clorita a partir da desestabilização de minerais ferromagnesianos primários.

\subsubsection{Feldspatos}

Foram realizadas análises em 16 fenocristais de plagioclásio, e 4 fenocristais de feldspato alcalino, e os dados representativos são mostrados na tabela 4 .

Os fenocristais de plagioclásios mostram composição variando de oligoclásio a andesina (Fig. 8A), com teores de anortita variando de $\mathrm{An}_{17 .}$ 39\%. Foram realizados cinco perfis (núcleo-borda) em fenocristais de plagioclásio. Todos os perfis analisados demonstram enriquecimento em sódio, e empobrecimento em cálcio do núcleo para a borda (zoneamento ígneo tipo normal). 0 conteúdo de $\mathrm{BaO}$ varia de $0 \%$ a $0,823 \%$.

Os feldspatos alcalinos analisados mostram composição variando de $\mathrm{Or}_{59} \mathrm{An}_{0} \mathrm{Ab}_{41}$ a $\mathrm{Or}_{92} \mathrm{~A}$ $\mathrm{n}_{0} \mathrm{Ab}_{08}$. $\mathrm{O}$ teor de $\mathrm{BaO}$ dos feldspatos alcalinos analisados varia de 0,5 a 1,8\%.

\subsubsection{Minerais Opacos}

Para os minerais opacos foram realizadas análises em 05 cristais (Tab. 5). Os minerais opacos 
Tabela 2. Composição química e proporções catiônicas $(\mathrm{O}=23)$ - Anfibólio/Amostras representativas. Table 2. Chemistry composition and cationic proportions $(\mathrm{O}=23)$ - Amphibole /Representative samples

\begin{tabular}{|c|c|c|c|c|c|c|c|c|}
\hline PP & \multicolumn{4}{|c|}{ Fácies 2} & \multicolumn{4}{|c|}{ Fácies 1} \\
\hline Amostra & $\mathrm{Jm} 17 \mathrm{c}$ & $\mathrm{Jm} 17 \mathrm{c} 2$ & $\mathrm{Jm} 17 \mathrm{c} 3$ & Jm17c4 & Jm28.1 & $\operatorname{Jm} 28.2$ & Jm29.9 & Jm29.11 \\
\hline $\mathrm{SiO}_{2}$ & 39,52 & 40,99 & 39,83 & 39,46 & 38,31 & 38,86 & 39,97 & 40,18 \\
\hline $\mathrm{TiO}_{2}$ & 1,30 & 1,55 & 1,83 & 1,75 & 1,02 & 1,35 & 1,26 & 1,66 \\
\hline $\mathrm{Al}_{2} \mathrm{O}_{3}$ & 10,82 & 10,18 & 10,79 & 10,51 & 11,54 & 11,38 & 11,99 & 11,68 \\
\hline $\mathrm{Fe}_{2} \mathrm{O}_{3}$ & 0,00 & 9,17 & 14,34 & 0,00 & 4,46 & 7,74 & 5,18 & 5,34 \\
\hline $\mathrm{FeO}$ & 27,00 & 27,20 & 26,97 & 26,28 & 23,31 & 21,93 & 22,48 & 22,29 \\
\hline $\mathrm{MnO}$ & 0,68 & 0,72 & 0,65 & 0,62 & 0,53 & 0,47 & 0,60 & 0,55 \\
\hline $\mathrm{MgO}$ & 3,25 & 3,33 & 3,54 & 3,42 & 2,43 & 2,67 & 3,26 & 3,47 \\
\hline $\mathrm{CaO}$ & 13,52 & 8,72 & 7,29 & 13,18 & 10,54 & 10,36 & 10,82 & 10,69 \\
\hline $\mathrm{Na}_{2} \mathrm{O}$ & 1,39 & 1,45 & 1,46 & 1,66 & 1,27 & 1,27 & 1,32 & 1,41 \\
\hline $\mathrm{K}_{2} \mathrm{O}$ & 1,81 & 1,69 & 1,77 & 1,76 & 1,80 & 1,76 & 1,77 & 1,69 \\
\hline $\mathrm{BaO}$ & 0,03 & 0,00 & 0,00 & 0,15 & 0,00 & 0,00 & 0,00 & 0,00 \\
\hline $\mathrm{F}$ & 0,73 & 0,76 & 0,80 & 0,67 & 0,23 & 0,47 & 0,25 & 0,28 \\
\hline $\mathrm{Cl}$ & 0,25 & 0,29 & 0,29 & 0,32 & 0,30 & 0,32 & 0,35 & 0,32 \\
\hline H2O & 1,48 & 1,47 & 1,45 & 1,49 & 1,65 & 1,58 & 1,71 & 1,71 \\
\hline Subtotal & 101,79 & 99,27 & 98,10 & 101,27 & 97,38 & 100,15 & 100,96 & 101,28 \\
\hline $\mathrm{O}=\mathrm{F}=\mathrm{Cl}$ & 0,36 & 0,39 & 0,40 & 0,35 & 0,17 & 0,27 & 0,19 & 0,19 \\
\hline Total & 101,43 & 98,89 & 97.70 & 100,91 & 97,22 & 99,88 & 100,78 & 101,09 \\
\hline $\mathrm{Si}$ & 6,26 & 6,46 & 6,29 & 6,27 & 6,26 & 6,17 & 6,25 & 6,25 \\
\hline $\mathrm{Al}^{\mathrm{IV}}$ & 1,73 & 1,53 & 1,71 & 1,72 & 1,74 & 1,82 & 1,74 & 1,74 \\
\hline $\mathrm{Al}^{\mathrm{VI}}$ & 0,28 & 0,35 & 0,30 & 0,24 & 0,48 & 0,30 & 0,46 & 0,40 \\
\hline $\mathrm{Ti}$ & 0,15 & 0,18 & 0,21 & 0,21 & 0,12 & 0,16 & 0,15 & 0,19 \\
\hline $\mathrm{Fe}^{3+}$ & 0,00 & 1,08 & 1,70 & 0,00 & 0,54 & 0,92 & 0,61 & 0,62 \\
\hline $\mathrm{Fe}^{2+}$ & 3,58 & 2,49 & 1,86 & 3,49 & 3,18 & 2,91 & 2,94 & 2,90 \\
\hline $\mathrm{Mn}$ & 0,09 & 0,09 & 0,09 & 0,08 & 0,07 & 0,06 & 0,08 & 0,07 \\
\hline $\mathrm{Mg}$ & 0,77 & 0,78 & 0,83 & 0,81 & 0,59 & 0,63 & 0,76 & 0,80 \\
\hline $\mathrm{Ca}$ & 2,29 & 1,47 & 1,23 & 2,24 & 1,84 & 1,76 & 1,81 & 1,78 \\
\hline $\mathrm{Na}$ & 0,43 & 0,44 & 0,45 & 0,51 & 0,40 & 0,39 & 0,40 & 0,42 \\
\hline K & 0,36 & 0,34 & 0,35 & 0,35 & 0,37 & 0,35 & 0,35 & 0,33 \\
\hline $\mathrm{Ba}$ & 0,00 & 0,00 & 0,00 & 0,01 & 0,00 & 0,00 & 0,00 & 0,00 \\
\hline $\mathrm{F}$ & 0,36 & 0,38 & 0,40 & 0,33 & 0,12 & 0,24 & 0,12 & 0,14 \\
\hline $\mathrm{Cl}$ & 0,07 & 0,07 & 0,08 & 0,08 & 0,08 & 0,08 & 0,09 & 0,08 \\
\hline $\mathrm{OH}$ & 1,56 & 1,54 & 1,52 & 1,57 & 1,79 & 1,67 & 1,78 & 1,77 \\
\hline Cation $^{\mathrm{T}}$ & 17,97 & 17,25 & 17,04 & 17,96 & 17,62 & 17,51 & 17,56 & 17,54 \\
\hline
\end{tabular}

identificados nos granitos do Plúton Pilõezinhos são, essencialmente, ilmenita (Fig. 8B). Cristais de magnetita ocorrem de forma isolada, de modo que em apenas uma análise (Fig. 8B) foi encontrada composição característica desse mineral. Ela apresentou baixo conteúdo de titânio $\left(\mathrm{TiO}_{2}<0,016\right)$, cromo $\left(\mathrm{Cr}_{2} \mathrm{O}_{3}<0,078\right)$ e vanádio $\left(\mathrm{V}_{2} \mathrm{O}_{3}<0,03\right)$.

\subsubsection{Titanita}

Foram realizadas análises em 4 cristais de titanita e os dados representativos são mostrados na tabela 6. Os cristais de titanita do grupo I nos granitos estudados ocorrem euédricos a subédricos inclusos em fases minerais posteriores, apresentam conteúdo de $\mathrm{CaO}$ entre $23 \%$ e $26 \%$, e de $\mathrm{TiO}_{2}$ entre $33 \%$ a $34 \%$. As titanitas do grupo I apresentam valores de $\mathrm{Al}_{2} \mathrm{O}_{3}$ entre $3,6 \%$ a $4,0 \%$, típicos dos tipos magmáticos, ao passo que os cristais secundários geralmente apresentam conteúdo de $\mathrm{Al}_{2} \mathrm{O}_{3}>6 \%$ (Tulloch, 1979; Enami et al., 1993).
Os teores de ETR (Fig. 9A) são baixos e os padrões normalizados para valores do condrito de Evesen et al. (1978) mostram grande variação, interpretada com resultante do baixo conteúdo de ETRL, bastante inferior ao conteúdo de ETR observado nas allanitas analisadas (Fig. 9B). Os baixos teores de ETRL observados sugerem que titanita foi uma fase cristalizada precocemente em relação às allanitas.

\subsubsection{Allanita}

Foram realizadas análises em 11 cristais de allanita e os dados representativos são mostrados na tabela 6. Grande parte dos cristais de allanita estudados, como sugerido por feições petrográficas, mostra certo grau de metamictização, fato refletido pelos baixos valores dos totais analíticos (< 93\%), o que dificulta o cálculo da fórmula estrutural de forma eficaz. No geral, apresentam conteúdo de $\mathrm{SiO}_{2}$ variando entre 11,5 e 33,3, $\mathrm{CaO}$ entre 5 e 
14,5\% e FeO entre 5 e 22,2\%. As análises de ETR nas allanitas do Plúton Pilõezinhos revelaram, em grande parte, conteúdo de $(\mathrm{ETR})^{\mathrm{T}}$ variando de 12,7 a 35,5 \% em óxido, com três amostras apresentando baixos teores de $\mathrm{SiO} 2, \mathrm{CaO}$ e $\mathrm{FeO}$, e elevados valores de $\left(\mathrm{ETR}^{\mathrm{T}}(54,5\right.$ a $67 \%$ de óxido). Os padrões de ETR são bastante fracionados (Fig. 9B), com picos em Ce, Nd e Gd, e alta concentração de ETRL em relação aos ETRP.

\subsection{Condições de cristalização}

Com base nos dados petrográficos e de química mineral do Plúton Pilõezinhos, foram inferidas as condições físico-químicas (pressão, temperatura e fugacidade de oxigênio) da cristalização dos granitos.

\subsubsection{Geotermômetro Anfibólio - Plagioclásio}

Para o cálculo de temperatura, foi utilizado o geotermômetro de anfibólio-plagioclásio, a partir da calibração de Blundy \& Holland (1990). Esse geotermômetro se baseia na presença de plagioclásio e anfibólio em equilíbrio em rochas saturadas em sílica. Dessa forma, é feita uma correlação entre os conteúdos de $\mathrm{Al}^{\mathrm{IV}}$ no anfibólio e de albita no plagioclásio, como função da temperatura. Essa calibração tem como referência as reações "edenita +4 quartzo = tremolita + albita", e "pargasita +4 quartzo $=$ hornblenda + albita". 0 valor da temperatura obtido na equação proposta por Blundy \& Holland (1990), é dada em ${ }^{\circ} \mathrm{K}$ com incerteza estimada em cerca de $\pm 75^{\circ} \mathrm{C}$, para rochas saturadas em sílica que se situam no intervalo de temperatura entre 500 e $1100^{\circ} \mathrm{C}$. A aplicabilidade desse geotermômetro é definida pela coexistência de anfibólio com $\mathrm{Si}<7,8$ pfu (números de átomos por fórmula) e plagioclásio com conteúdo de An < 92\%, ambas condições atendidas para os granitos estudados. Assim, as temperaturas de cristalização calculadas para os granitos do Plúton Pilõezinhos variam entre 745 e $795 \pm 75^{\circ} \mathrm{C}$ (Tabela 7).

Tabela 3. Composição química e proporções catiônicas $(\mathrm{O}=24)$ - Clorita/Amostras representativas.

Table 3. Chemical composition and cationic proportions $(\mathrm{O}=24)$ - Chlorite/Representative samples.

\begin{tabular}{|c|c|c|c|c|c|c|c|}
\hline PP & \multicolumn{7}{|c|}{ Fácies 1} \\
\hline Amostra & Jm11.1 & Jm11.2 & $\mathrm{Jm} 11.3$ & Jm11.4 & Jm11.5 & Jm11.6 & Jm11.7 \\
\hline $\mathrm{SiO}_{2}$ & 23,18 & 25,73 & 24,15 & 23,84 & 23,43 & 24,54 & 23,80 \\
\hline $\mathrm{TiO}_{2}$ & 0,16 & 0,06 & 0,00 & 0,04 & 0,11 & 0,23 & 0,16 \\
\hline $\mathrm{Al}_{2} \mathrm{O}_{3}$ & 21,05 & 18,25 & 20,54 & 20,27 & 20,81 & 19,02 & 19,65 \\
\hline $\mathrm{Fe}_{2} \mathrm{O}_{3}$ & 19,93 & 20,85 & 20,01 & 20,29 & 20,25 & 20,22 & 19,67 \\
\hline $\mathrm{FeO}$ & 20,36 & 20,57 & 20,09 & 19,37 & 19,77 & 20,83 & 20,90 \\
\hline $\mathrm{MnO}$ & 0,39 & 0,26 & 0,32 & 0,31 & 0,30 & 0,26 & 0,32 \\
\hline $\mathrm{MgO}$ & 5,23 & 6,26 & 5,97 & 5,64 & 6,16 & 5,93 & 6,25 \\
\hline $\mathrm{CaO}$ & 0,00 & 0,37 & 2,60 & 0,50 & 0,00 & 0,00 & 0,82 \\
\hline $\mathrm{Na} 20$ & 0,30 & 0,06 & 0,01 & 0,07 & 0,03 & 0,09 & 0,10 \\
\hline K2O & 0,14 & 0,04 & 0,04 & 0,06 & 0,01 & 0,04 & 0,05 \\
\hline $\mathrm{F}$ & 0,24 & 0,26 & 0,20 & 0,20 & 0,25 & 0,16 & 0,26 \\
\hline $\mathrm{Cl}$ & 0,13 & 0,01 & 0,00 & 0,02 & 0,00 & 0,03 & 0,00 \\
\hline $\mathrm{H}_{2} \mathrm{O}$ & 10,93 & 9,40 & 8,07 & 11,50 & 10,90 & 10,50 & 10,00 \\
\hline $\mathrm{O}=\stackrel{\mathrm{F}}{\mathrm{F}}=\mathrm{Cl}$ & 0,13 & 0,11 & 0,08 & 0,09 & 0,11 & 0,07 & 0,11 \\
\hline Total & 101,09 & 102,04 & 101,99 & 102,06 & 101,98 & 101,96 & 101,97 \\
\hline $\mathrm{Si}$ & 4,17 & 4,55 & 4,23 & 4,30 & 4,20 & 4,42 & 4,26 \\
\hline $\mathrm{Al}^{\mathrm{IV}}$ & 3,82 & 3,44 & 3,76 & 3,69 & 3,79 & 3,57 & 3,73 \\
\hline $\mathrm{Al}^{\mathrm{VI}}$ & 0,94 & 0,61 & 0,75 & 0,90 & 0,89 & 0,71 & 0,68 \\
\hline $\mathrm{Ti}$ & 0,02 & 0,00 & 0,00 & 0,00 & 0,01 & 0,03 & 0,02 \\
\hline $\mathrm{Fe}^{3+}$ & 2,70 & 2,77 & 2,64 & 2,75 & 2,73 & 2,74 & 2,65 \\
\hline $\mathrm{Fe}^{2+}$ & 3,06 & 3,04 & 2,94 & 2,92 & 2,97 & 3,13 & 3,13 \\
\hline $\mathrm{Mn}$ & 0,06 & 0,04 & 0,05 & 0,04 & 0,04 & 0,04 & 0,05 \\
\hline $\mathrm{Mg}$ & 1,40 & 1,65 & 1,56 & 1,51 & 1,65 & 1,59 & 1,67 \\
\hline $\mathrm{Ca}$ & 0,00 & 0,07 & 0,49 & 0,09 & 0,00 & 0,00 & 0,15 \\
\hline $\mathrm{Na}$ & 0,21 & 0,04 & 0,01 & 0,05 & 0,02 & 0,07 & 0,07 \\
\hline $\mathrm{K}$ & 0,06 & 0,02 & 0,01 & 0,03 & 0,00 & 0,01 & 0,02 \\
\hline $\mathrm{F}$ & 0,27 & 0,30 & 0,22 & 0,23 & 0,29 & 0,18 & 0,29 \\
\hline $\mathrm{Cl}$ & 0,08 & 0,01 & 0,00 & 0,01 & 0,00 & 0,01 & 0,00 \\
\hline $\mathrm{OH}$ & 15,64 & 15,69 & 15,78 & 17,75 & 15,70 & 15,79 & 15,70 \\
\hline Cations $^{\mathrm{T}}$ & 32,48 & 32,27 & 32,48 & 32,34 & 32,35 & 32,37 & 32,47 \\
\hline Fe\# & 0,80 & 0,78 & 0,78 & 0,78 & 0,77 & 0,78 & 0,77 \\
\hline
\end{tabular}



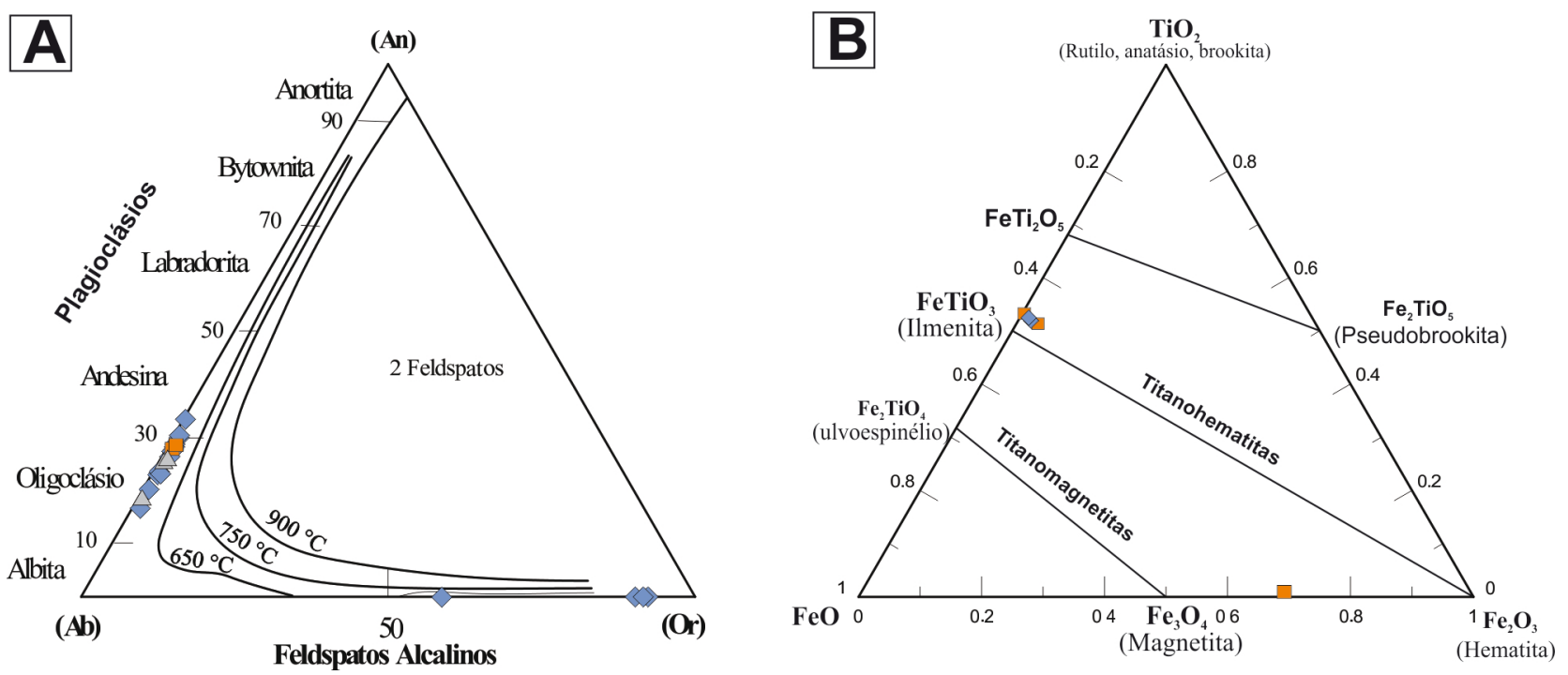

Figura 8. Diagramas químicos para classificação dos feldspatos e óxidos estudados. A) Diagrama ternário An-Ab-Or para classificação dos feldspatos estudados (modificado de Deer et al., 1992); B) Diagrama ternário $\mathrm{Fe}_{2} \mathrm{O}_{3} \times \mathrm{TiO}_{2} \times \mathrm{FeO}$ para os óxidos estudados (adaptado a partir de Buddington \& Lindsley, 1964). Símbolos como na figura 3.

Figure 8. Chemical diagrams for feldspars and oxides classification. A) Ternary diagram An-Ab-Or for classification of the studied feldspar (modified by Deer et al., 1992); B) Ternary diagram $\mathrm{Fe}_{2} \mathrm{O}_{3} \times \mathrm{TiO}_{2} \times \mathrm{FeO}$ for the classification of the studied oxides (adapted from Buddington \& Lindsley, 1964). Symbols as figure 3.

Tabela 4. Composição química e proporções catiônicas $(\mathrm{O}=24)$ - Feldspatos/Amostras representativas. Legenda: $\mathrm{C}=$ centro; $\mathrm{B}$ $=$ borda

Table 4. Chemical composition and cationic proportions $(\mathrm{O}=24)$ - Feldspars /Representative samples. Subtitle: $C=$ center; $B=$ border

\begin{tabular}{c|cc|cc|ccc|ccc}
\hline PP & \multicolumn{2}{|c|}{$\begin{array}{c}\text { Enclaves } \\
\text { (Plagioclásio) }\end{array}$} & \multicolumn{2}{c|}{$\begin{array}{c}\text { Fácies 2 } \\
\text { (Plagioclásio) }\end{array}$} & \multicolumn{3}{c|}{$\begin{array}{c}\text { Fácies 1 } \\
\text { (Plagioclásio) }\end{array}$} & \multicolumn{3}{c}{$\begin{array}{c}\text { Fácies 1 } \\
\text { (Feldspato alcalino) }\end{array}$} \\
\hline Amostras & Jm9b.1 & Jm9b.2 & Jm17c.1 & Jm17c.2 & Jm4.2 & Jm28.1 & Jm28.1 & Jm29.1 & Jm4.2 & Jm4.3 \\
Posição & - & - & - & - & - & $\mathrm{B}$ & $\mathrm{C}$ & - & - & - \\
$\mathrm{SiO}_{2}$ & 63,47 & 63,12 & 63,21 & 60,70 & 61,08 & 63,31 & 61,14 & 64,36 & 65,59 & 63,38 \\
$\mathrm{Al}_{2} \mathrm{O}_{3}$ & 22,88 & 23,17 & 23,25 & 24,27 & 24,35 & 22,99 & 23,83 & 19,00 & 19,20 & 18,67 \\
$\mathrm{FeO}$ & 0,00 & 0,00 & 0,02 & 0,02 & 0,00 & 0,00 & 0,00 & 0,04 & 0,08 & 0,01 \\
$\mathrm{CaO}$ & 3,72 & 5,51 & 5,22 & 5,48 & 3,26 & 4,07 & 5,19 & 0,00 & 0,00 & 0,00 \\
$\mathrm{BaO}$ & 0,09 & 0,00 & 0,00 & 0,02 & 0,01 & 0,00 & 0,00 & 1,80 & 0,55 & 0,89 \\
$\mathrm{Na}_{2} \mathrm{O}$ & 9,39 & 9,29 & 7,52 & 8,39 & 8,52 & 8,81 & 9,35 & 0,89 & 4,53 & 0,94 \\
$\mathrm{~K}_{2} \mathrm{O}$ & 0,22 & 0,24 & 0,19 & 0,24 & 0,18 & 0,15 & 0,22 & 15,61 & 9,80 & 15,30 \\
$*$ & 0,03 & 0,03 & 0,07 & 0,16 & 0,14 & 0,04 & 0,00 & 0,00 & 0,15 & 0,12 \\
$\mathrm{Total}$ & 99,80 & 101,07 & 99,50 & 99,31 & 99,67 & 99,40 & 99,75 & 101,73 & 99,92 & 99,32 \\
$\mathrm{Ab}$ & 80,98 & 74,35 & 71,40 & 72,45 & 81,58 & 78,93 & 75,62 & 7,97 & 41,26 & 8,54 \\
$\mathrm{An}$ & 17,75 & 24,36 & 27,38 & 26,16 & 17,29 & 20,14 & 23,21 & 0,00 & 0,00 & 0,00 \\
Or & 1,26 & 1,28 & 1,21 & 1,38 & 1,12 & 0,91 & 1,15 & 92,02 & 58,73 & 91,45 \\
\hline
\end{tabular}

Tabela 5. Composição química - Óxido/Amostras representativas.

Table 5. Chemical composition - Oxide/Representative samples.

\begin{tabular}{c|cc|ccc}
\hline PP & \multicolumn{2}{|c|}{ Fácies 1} & \multicolumn{3}{c}{ Fácies 2} \\
\hline Amostras & Jm11.1 & Jm11.2 & Jm17.1 & Jm17.2 & Jm17.3 \\
$\mathrm{Cr}_{2} \mathrm{O}_{3}$ & 0,00 & 0,01 & 0,00 & 0,00 & 0,00 \\
$\mathrm{Al}_{2} \mathrm{O}_{3}$ & 0,00 & 0,10 & 0,05 & 0,04 & 0,01 \\
$\mathrm{TiO}_{2}$ & 50,36 & 49,64 & 0,01 & 51,84 & 49,21 \\
$\mathrm{FeO}$ & 43,45 & 42,83 & 26,40 & 44,31 & 42,42 \\
$\mathrm{Fe}_{2} \mathrm{O}_{3}$ & 2,68 & 1,19 & 60,31 & 0,70 & 2,78 \\
$\mathrm{MgO}$ & 0,01 & 0,04 & 0,40 & 0,02 & 0,04 \\
$\mathrm{MnO}$ & 2,45 & 2,34 & 0,00 & 2,81 & 2,35 \\
$\mathrm{NiO}$ & 0,00 & 0,00 & 0,00 & 0,00 & 0,00 \\
$\mathrm{~V}_{2} \mathrm{O}_{3}$ & 0,41 & 0,39 & 0,03 & 0,36 & 0,38 \\
$\mathrm{OH}$ & 0,58 & 2,36 & 13,86 & 0,00 & 2,53 \\
$\mathrm{Total}$ & 99,97 & 98,93 & 101,07 & 100,09 & 99,74 \\
\hline \multicolumn{5}{r}{}
\end{tabular}



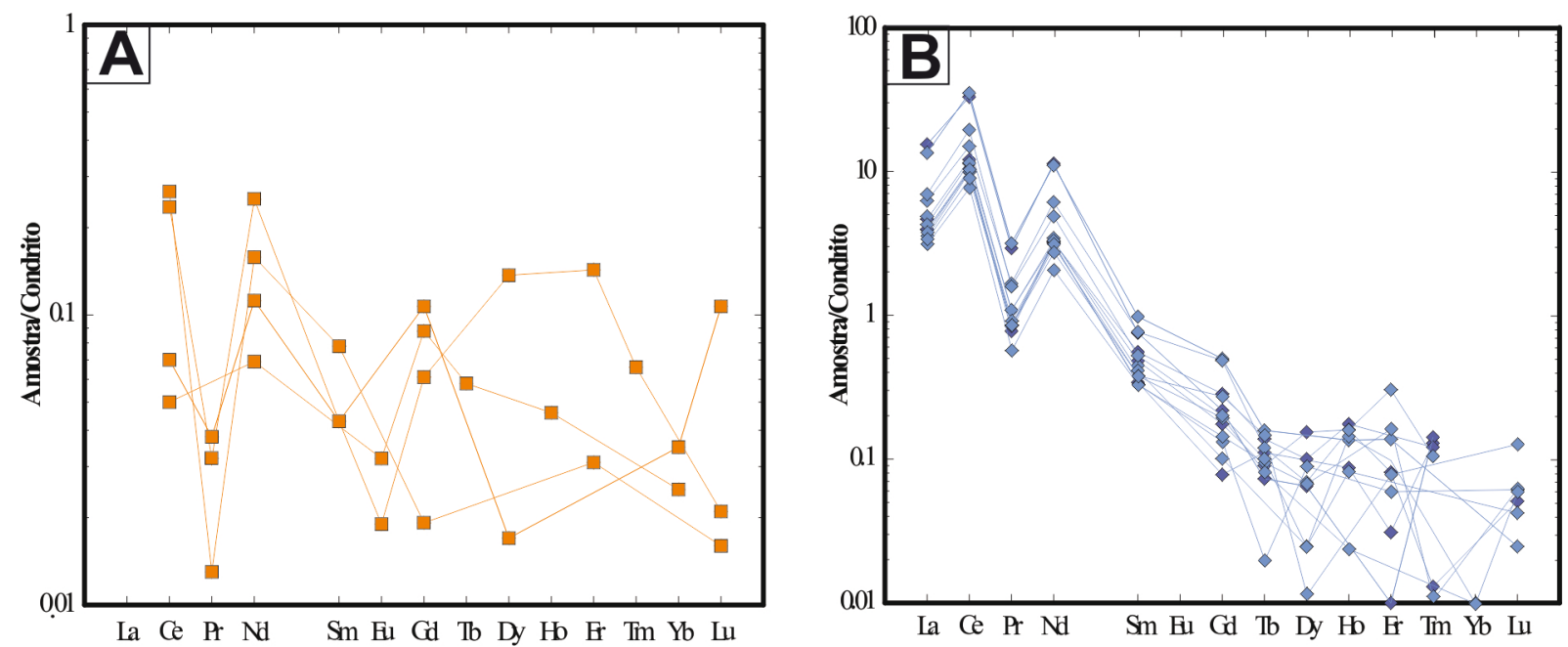

Figura 9. Padrões de ETR normalizados para valores sugeridos por Evensen et al. (1978) para os principais minerais acessórios analisados. A) Padrão de ETR para as titanitas estudados; B) Padrão de ETR para as allanitas analisadas. Símbolos como na figura 3.

Figure 9. REE patterns normalized to the values suggested by Evensen et al. (1978) for the main analyzed accessory minerals. A) REE patterns for the studied titanites; B) REE patterns for the analyzed allanites. Symbols as figure 3.

Tabela 6. Composição química $(\mathrm{O}=24)$ - Allanita e Titanita/Amostras representativas. Legenda: $\mathrm{C}=$ centro; $\mathrm{B}=\mathrm{borda}$. Table 6. Chemical composition $(O=24)$-Allanite and Titanite/Representative samples. Subtitle: $C=c e n t e r ; B=b o r d e r$.

\begin{tabular}{|c|c|c|c|c|c|c|c|c|}
\hline PP & \multicolumn{5}{|c|}{ Alanitta - Fácies 1} & \multicolumn{3}{|c|}{ Titanita - Fácies 2} \\
\hline Amostra & Jm11.1 & $\operatorname{Jm} 11.2$ & Jm11.6 & Jm4.3 & Jm4.5 & Jm17.1 & $\operatorname{Jm} 17.2$ & Jm17.3 \\
\hline Posição & $\mathrm{C}$ & $\mathrm{B}$ & - & - & - & - & - & - \\
\hline $\mathrm{SiO}_{2}$ & 27,22 & 1,66 & 2,89 & 20,93 & 32,85 & 30,21 & 29,18 & 30,03 \\
\hline $\mathrm{Al}_{2} \mathrm{O}_{3}$ & 12,49 & 0,66 & 1,10 & 6,97 & 16,16 & 4,06 & 3,87 & 3,66 \\
\hline $\mathrm{F}$ & 0,66 & 7,85 & 7,46 & 3,50 & 0,17 & 1,61 & 1,78 & 1,74 \\
\hline $\mathrm{TiO}_{2}$ & 1,49 & 0,77 & 0,38 & 1,57 & 0,60 & 33,60 & 34,34 & 33,24 \\
\hline $\mathrm{CaO}$ & 7,74 & 4,86 & 5,75 & 7,70 & 12,25 & 26,50 & 26,72 & 23,87 \\
\hline $\mathrm{FeO}$ & 11,52 & 1,07 & 1,34 & 5,02 & 9,36 & 1,30 & 1,16 & 1,31 \\
\hline $\mathrm{OH}$ & 0,00 & 0,00 & 0,00 & 0,00 & 0,00 & 2,12 & 2,59 & 5,07 \\
\hline Total & 60,86 & 13,58 & 15,80 & 44,24 & 71,35 & 99,4 & 99,73 & 98,92 \\
\hline $\mathrm{Si}$ & 6,75 & 3,39 & 4,45 & 7,27 & 6,78 & 4,72 & 4,53 & 4,55 \\
\hline $\mathrm{Al}$ & 3,65 & 1,59 & 1,99 & 2,85 & 3,93 & 0,73 & 0,69 & 0,68 \\
\hline $\mathrm{F}$ & 0,51 & 16,28 & 14,44 & 3,31 & 0,11 & 0,76 & 0,83 & 0,78 \\
\hline $\mathrm{Ti}$ & 0,27 & 1,18 & 0,45 & 0,41 & 0,09 & 3,87 & 3,95 & 3,67 \\
\hline $\mathrm{Ca}$ & 2,05 & 10,61 & 9,47 & 2,86 & 2,71 & 4,35 & 4,38 & 3,75 \\
\hline $\mathrm{Fe}$ & 2,39 & 1,83 & 1,72 & 1,46 & 1,61 & 0,16 & 0,15 & 0,16 \\
\hline $\mathrm{OH}$ & 0,00 & 0,00 & 0,00 & 0,00 & 0,00 & 2,16 & 2,65 & 4,98 \\
\hline Cations $^{\mathrm{T}}$ & 15,65 & 34,90 & 32,54 & 18,19 & 15,26 & 16,86 & 17,31 & 18,69 \\
\hline $\mathrm{Ho}_{2} \mathrm{O}_{3}$ & 0,08 & 0,00 & 0,00 & 0,08 & 0,09 & 0,00 & 0,04 & 0,00 \\
\hline $\mathrm{Er}_{2} \mathrm{O}_{3}$ & 0,03 & 0,01 & 0,00 & 0,00 & 0,04 & 0,00 & 0,00 & 0,14 \\
\hline $\mathrm{Tm}_{2} \mathrm{O}_{3}$ & 0,13 & 0,14 & 0,00 & 0,00 & 0,02 & 0,00 & 0,00 & 0,06 \\
\hline $\mathrm{Yb}_{2} \mathrm{O}_{3}$ & 0,00 & 0,00 & 0,00 & 0,00 & 0,00 & 0,03 & 0,02 & 0,00 \\
\hline $\mathrm{Lu}_{2} \mathrm{O}_{3}$ & 0,00 & 0,00 & 0,03 & 0,04 & 0,02 & 0,10 & 0,00 & 0,02 \\
\hline $\mathrm{PbO}$ & 0,02 & 0,00 & 0,00 & 0,06 & 0,21 & 0,06 & 0,00 & 0,12 \\
\hline $\mathrm{Sm}_{2} \mathrm{O}_{3}$ & 0,34 & 0,75 & 1,34 & 0,53 & 0,11 & 0,04 & 0,00 & 0,04 \\
\hline $\mathrm{Eu}_{2} \mathrm{O}_{3}$ & 0,00 & 0,00 & 0,00 & 0,00 & 0,00 & 0,00 & 0,03 & 0,02 \\
\hline $\mathrm{Gd}_{2} \mathrm{O}_{3}$ & 0,08 & 0,21 & 0,42 & 0,20 & 0,00 & 0,10 & 0,09 & 0,06 \\
\hline $\mathrm{Tb}_{2} \mathrm{O}_{3}$ & 0,11 & 0,07 & 0,00 & 0,10 & 0,11 & 0,00 & 0,06 & 0,00 \\
\hline $\mathrm{Dy}_{2} \mathrm{O}_{3}$ & 0,00 & 0,06 & 0,20 & 0,02 & 0,00 & 0,01 & 0,00 & 0,13 \\
\hline $\mathrm{ThO}_{2}$ & 0,73 & 1,51 & 3,70 & 1,36 & 0,71 & 0,00 & 0,00 & 0,00 \\
\hline $\mathrm{La}_{2} \mathrm{O}_{3}$ & 4,64 & 15,4 & 11,56 & 7,00 & 2,48 & 0,00 & 0,00 & 0,00 \\
\hline $\mathrm{Ce}_{2} \mathrm{O}_{3}$ & 12,05 & 32,93 & 26,18 & 19,62 & 6,70 & 0,07 & 0,05 & 0,23 \\
\hline $\mathrm{Pr}_{2} \mathrm{O}_{3}$ & 1,08 & 2,92 & 2,24 & 1,60 & 0,48 & 0,04 & 0,00 & 0,03 \\
\hline $\mathrm{Nd}_{2} \mathrm{O}_{3}$ & 3,16 & 11,32 & 8,74 & 4,91 & 1,60 & 0,11 & 0,07 & 0,25 \\
\hline $\mathrm{UO}_{2}$ & 0,04 & 0,05 & 0,04 & 0,00 & 0,02 & 0,00 & 0,00 & 0,05 \\
\hline $\begin{array}{r}2 \\
\text { ETR }^{\mathrm{T}} \\
\end{array}$ & 22,52 & 65,40 & 54,48 & 35,56 & 12,62 & 0,58 & 0,37 & 1,18 \\
\hline
\end{tabular}




\subsubsection{Geobarômetro Alumínio Total em hornblenda}

O cálculo da pressão baseado no conteúdo de alumínio total em cristais de hornblenda foi inicialmente formulado através de equações empíricas por Hammarstrom \& Zen (1986), e Hollister et al. (1987). Posteriormente esse geotermômetro foi calibrado para a assembleia quartzo + K-feldspato + plagioclásio + hornblenda + biotita + titanita + melt + fluído (Johnson \& Rutheford, 1989; Thomas \& Ernst, 1990; Schmidt, 1992). A equação proposta por Schmidt (1992), no entanto, não é adequada às rochas graníticas do Plúton Pilõezinho, devido ao fato dessas apresentarem uma faixa de temperatura mais alta do que esperado em rochas estudadas nessa calibração $\left(655-700^{\circ} \mathrm{C}\right)$. Dessa forma, foi utilizada a calibração de Anderson \& Smith (1995), que leva em consideração um valor de correção de temperatura para que a equação se adeque as temperaturas de cristalização mais elevadas de rochas graníticas, onde pode haver acréscimo de $\mathrm{Al}^{\mathrm{IV}}$ na hornblenda, ou sob condições de baixa fugacidade de oxigênio. Segundo o geotermômetro de Anderson \& Smith (1995), a pressão na qual os granitos estudados foram cristalizados, varia de 4,28 a 5,95 $\pm 0,6 \mathrm{Kbar}$ (Tab. 7). Os valores da pressão, considerados baixo a médio, podem ser explicados pelas estruturas de transcorrência associadas ao plúton, onde o magma granítico ascenderia com relativa facilidade ao longo de condutos verticalizados através de encaixantes aquecidas, até um nível mais alto da crosta.

\subsubsection{Geotermometria de saturação em $\mathrm{Zr}$}

Esse geotermômetro se baseia no princípio de que o coeficiente de partição do zircônio $\left(\mathrm{Kd}_{\mathrm{zr}}\right) \mathrm{em}$ magmas félsicos crustais é função da temperatura (Watson, 1979; Watson \& Harrison, 1983; 1984). Dessa forma, pode ser usada o teor em $\mathrm{Zr}$ na rocha, para se estimar a temperatura de cristalização do zircão em líquidos saturados em $\mathrm{Zr}$ (Watson, 1987), porém algumas condições são necessárias para a utilização desse geotermômetro: temperatura entre $700^{\circ} \mathrm{C}$ a $1000^{\circ} \mathrm{C}$, cristalização precoce de zircão, diminuição dos teores de zircônio em rochas sucessivamente mais diferenciada, como evidenciada através da correlação negativa entre $\mathrm{Zr}$ e $\mathrm{T}\left({ }^{\circ} \mathrm{C}\right.$ ), e $\mathrm{Zr}$ e $\mathrm{SiO}_{2}$ (Lima et al., 2015b), e valor da razão [(Na+K+2Ca)/(Si*Al)] entre 0,9-1,7 (Watson \& Harrison, 1983; Watson, 1987). Nos granitos estudados, as temperaturas baseada na saturação do $\mathrm{Zr}$ (Lima et al., 2015b) são mais elevadas $\left(872^{\circ} \mathrm{C}\right.$ a $1004^{\circ} \mathrm{C}$ ) (Fig. $10 \mathrm{~A}$ ) que aquelas obtidas pelo geo- termômetro anfibólio-plagioclásio. Como o zircão é uma das fases mais precoces na cristalização do magma, é esperado que este geotermômetro forneça temperaturas mais elevadas, as quais podem ser interpretadas como a temperatura mínima da líquidus.

\subsubsection{Fugacidade de Oxigênio}

A fugacidade de oxigênio de um magma é um parâmetro relacionado com a sua fonte (Loiselle \& Wones, 1979; Gill, 1981; Wones, 1989; Ishihara, 1998), e dependente da pressão e temperatura (Wones, 1989), exercendo importante controle na assembleia e composição química dos minerais em rochas ígneas (Abbott \& Clarke, 1979; Abott, 1985). 0 alto conteúdo de ferro observado nos cristais de biotita e anfibólio do Plúton Pilõezinhos é típico de cristalização em condições de baixa $\mathrm{fO}_{2}$, comprovado pela presença de ilmenita primária. A $\mathrm{fO}_{2}$ dos granitos estudados foi quantificada a partir da equação proposta por Wones (1989), que representa a reação hedenbergita + ilmenita + oxigênio = titanita + magnetita + quartzo em função da $\mathrm{fO}_{2}$, $\mathrm{P}$ e T. $\mathrm{O}$ valor da $\mathrm{fO}_{2}$ obtido por essa equação varia de $10^{-16}$ a $10^{-19}$, sugerindo que o magma granítico cristalizou abaixo do tampão FMQ no diagrama Log $\mathrm{fO}_{2}$ versus Temperatura (Fig. 10B), corroborando assim para cristalização em condições de baixa fugacidade como indicada pela composição dos minerais máficos deste Plúton.

\section{Discussão dos resultados}

Os dados de campo sugerem que os granitos do Plúton Pilõezinhos foram intrudidos em sítios extensionais, associados à movimentação sincrônica da ZCRP de direção E-W e cinemática destral, e a Zona de Cisalhamento Matinhas de direção NE-SW e cinemática sinistral. A continuidade no processo deformacional, demonstrada por feições de campo (foliação magmática e trama S-C) e microfeições de deformação (zoneamento ígneo, textura chessboard em quartzo, intercrescimento mirmequitico e fraturas), juntamente com as direções das foliações paralelas a ZCRP, caracterizam esse plúton como sin-transcorrente, feição bastante observada no Domínio Transversal da Província Borborema (Neves et al., 2006).

As composições mineralógicas de ambas as fácies petrográficas são semelhantes, divergindo apenas nas proporções modais e texturas observadas. Os feldspatos alcalinos são representados por cristais de microclínio e pertita, enquanto os 
Tabela 7. Dados de pressão e temperatura para os granitos estudados obtidos pelos métodos do Geobarômetro $\mathrm{Al}^{\mathrm{T}}$ em Hornblendas e Geotermômetro Anfibólio - Plagioclásio.

Table 7. Pressure and temperature data for the studied granites, obtained by the Geobarometer AlT in hornblende and Geothermometer using amphibole - plagioclase pair.

\begin{tabular}{c|cc|ccccccc}
\hline $\begin{array}{c}\text { Plúton } \\
\text { Pilõezinhos }\end{array}$ & $\begin{array}{c}\text { Monzogranitos } \\
\text { equigranulares de } \\
\text { granulação fina }\end{array}$ & & \multicolumn{5}{c}{ Sienogranito a monzogranito grosso porfirítico } \\
\hline $\begin{array}{c}\mathrm{T} \\
\left( \pm 75^{\circ} \mathrm{C}\right) \\
\mathrm{P}\end{array}$ & 770,21 & 745,04 & 759,31 & 789,3 & 778,90 & 794,52 & 778,66 & 791,56 & 775,06 \\
\begin{tabular}{c} 
$\pm 0,6$ Kbar $)$ \\
\hline
\end{tabular} & 4,62 & 4,86 & 5,95 & 4,80 & 5,15 & 5,01 & 5,98 & 4,28 & 5,54 \\
\hline
\end{tabular}

feldspatos calcossódicos variam em composição de oligoclásio a andesina. A biotita apresenta altos valores de ferro, é rica na molécula de siderofilita e apresenta assinatura química semelhante às observadas em cristais de biotita originados a partir de magmatismo alcalino anorogênico (granitos) e cálcio-alcalino (enclaves) (Abdel-Rahman, 1994), concordando com o caráter alcalino do Plúton Pilõezinhos evidenciado na química de rocha total (Lima et al., 2015a). Os cristais de anfibólio analisados são enriquecidos em ferro e mostram composição variando de hastingsita a Fe-tchermakita, inclusive com razões de Fe\# semelhantes às observadas na química de rocha total (Lima et al., 2015a). A mineralogia acessória compreende titanita, zircão, apatita, ilmenita, magnetita e allanita.

A composição dos principais minerais máficos do Plúton Pilõezinhos é caracterizada pelo enriquecimento em ferro, sugerindo que o magma progenitor evoluiu sob condições redutoras, fato corroborado pela projeção desses granitos abaixo do tampão FMQ no diagrama $\log \mathrm{fO}_{2}$ versus $\mathrm{T}$, e pela presença ilmenita primária, que em granitos tipo-A sugere evolução sob condições de baixa $\mathrm{fO}_{2}$ (King et al., 1997). 0 conteúdo de $\mathrm{Al}^{\mathrm{T}}$ obtido em hornblenda sugere, a partir do geobarômetro de Schmidt (1992), que a pressão de cristalização dos granitos estudados oscilou entre 4,28 e 5,95 Kbars. O geotermômetro de Blundy \& Holland, (1990), utilizado para determinação das temperaturas de cristalização, forneceu temperaturas variando de 745 a $795^{\circ} \mathrm{C}$. As temperaturas calculadas com base na saturação de $\mathrm{Zr}$ desses granitos segundo os procedimentos de Watson \& Harrison (1983) e Watson (1987) variam de 872,4 a $1003,7^{\circ} \mathrm{C}$, superiores àquelas obtidas pelo geotermômetro anfibólio - plagioclásio, sendo interpretadas como temperaturas estimadas para a líquidus do magma.

A ação de fluidos tardios induzindo a assembleia mineral pré-formada a um reequilíbrio em estágio subsolidus (alteração hidrotermal) foi evidenciado pela presença de clorita, resultante da desestabilização dos minerais ferromagnesianos primários, sericitização de plagioclásio, intercrescimento mirmequítico demonstrado na petrografia, e biotitas, ainda que em pequena quantidade, com baixo conteúdo de $\mathrm{TiO}_{2}$, e alto conteúdo de [FeO + $\mathrm{MnO}]$ (biotitas reequilibradas), além da presença das finas coroas de titanita em minerais opacos. Estas alterações ocorreram provavelmente em condições de temperatura entre 505 e 566 ${ }^{\circ} \mathrm{C}$, como indicado pelo geotermômetro da clorita proposto por Jowett (1991).

A análise de ETR nos principais minerais acessórios, aqueles que apresentam maior percentagem modal, confirmou que a allanita é o mineral que mais contém ETR nos granitos estudados. A presença de zonação nessas allanitas, assim como em K-feldspatos e plagioclásio, sugere que cristalização fracionada foi um processo importante durante a evolução magmática dos granitos do Plúton Pilõezinhos.

A composição mineralógica, o contexto estrutural e o enriquecimento em ferro dos principais minerais máficos do Plúton Pilõezinhos, além da presença de ilmenita primária, são feições semelhantes às descritas em granitos tipo-A aluminosos por King et al. (1997) na Faixa Dobrada de Lachlan no sudoeste da Austrália. King et al. (1997) sugerem que a temperatura de saturação de $\mathrm{Zr}$ em granitos tipo-A aluminosos, é relativamente mais elevada que em outros tipos de granitos e, que o enriquecimento em $\mathrm{Zr}$ e outros HFSE observados em granitos tipo-A resulta da dependência do coeficiente de partição destes elementos com a temperatura. 0 modelo petrogenético sugerido por King et al. (1997) para granitos tipo-A aluminosos, baseia-se na derivação a partir de fusão parcial de material infracrustal. Os granitos do Plúton Pilõezinhos mostram elevados teores de HFSE e assinatura química características de rochas derivadas a partir da fusão material infracrustal (Lima et al., 2015a). 

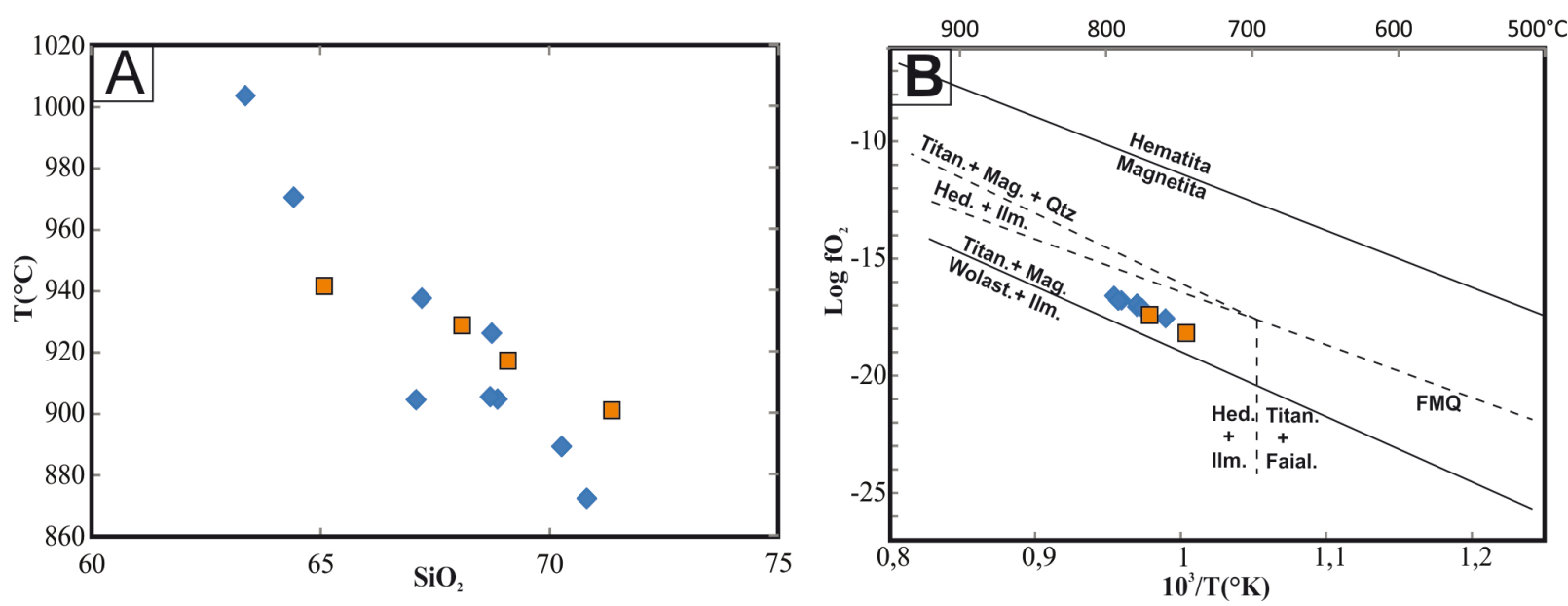

Figura 10. Parâmetros físicos envolvidos na evolução magmática dos granitos estudados. A) Diagrama $\operatorname{Si} \mathrm{x}\left({ }^{\circ} \mathrm{C}\right)$ para os granitos estudados com base nos valores de zircônio (Watson \& Harrison, 1983); B) Fugacidade de oxigênio dos granitos estudados quantificada através do diagrama $\log \mathrm{fO}_{2}$ versus $10^{3} / \mathrm{T}(\mathrm{k})$ (Wones, 1989). Símbolos como na figura 3.

Figure 10. Physical parameters involved in the magmatic evolution of the studied granites. A) Diagram Si $x$ T $\left({ }^{\circ} \mathrm{C}\right)$ for the studied granites based on $\mathrm{Zr}$ whole rocks contents (Watson \& Harrison, 1983); B) Log fO ${ }_{2}$ versus $10^{3} / \mathrm{T}(\mathrm{k})$ diagram to evaluate the oxygen fugacity of the studied granites. Symbols as figure 3.

\section{Conclusões}

O Plúton Pilõezinhos é composto por granitos que foram subdivididos em duas fácies petrográficas principais: fácies 1 - sienogranito grosso porfirítico, contendo raros enclaves dioríticos e xenólitos das encaixantes; e fácies 2 - monzogranitos equigranulares de granulação fina.

As feições mineralógicas, químicas e estruturais presentes nesses granitos são semelhantes às de granitos tipo- $\mathrm{A}_{2}$ ou "tipo-A aluminoso". Essas incluem: contexto extensional associado à intrusão, biotita rica em ferro, anfibólios hastingsíticos, e presença de allanita, titanita e ilmenita primária como minerais acessórios.

0 estudo de química mineral, associado aos dados de campo e petrografia, permitiu estabelecer os parâmetros físico-químicos associados às condições de cristalização do magma granítico estudado. Esses dados evidenciaram que:

i) As condições em que os granitos cristalizaram foram caracterizadas por temperaturas no intervalo de 745 a cerca de $1000^{\circ} \mathrm{C}$ (geotermômetro anfibólio - plagioclásio e geotermômetro do Zr), e pressão variando de 4,28 a 5,95 Kbar (geobarômetro $\mathrm{Al}^{\mathrm{T}}$ em hornblendas);

ii) A fugacidade de oxigênio calculada situou-se abaixo do tampão FMQ;

iii) Houve atuação de fluidos tardios gerando uma mineralogia secundária, sobre condições de temperaturas variando de 505 a $566{ }^{\circ} \mathrm{C}$ (geotermômetro da clorita);

iv) Cristalização fracionada foi um processo importante e talvez dominante durante a evolução magmática do Plúton Pilõezinhos.

\section{Referências}

Abbott, J.R.N. 1985. Muscovite-bearing granites in the AFM liquidus projection. Canadian Mineralogist, 23: 553-561.

Abbott, J.R.N. \& Clarke, D.B. 1979. Hypothetical liquidus relationships in the subsystem Al2O3-FeO$\mathrm{MgO}$ projected from quartz, alkali feldspar and plagioclase for a $\left(\mathrm{H}_{2} \mathrm{O}\right)=1$. Canadian Mineralogist, 17: 549-560.

Abdel-Rahman, A.M. 1994. Nature of biotites from alkaline, calc-alkaline, and Peraluminous magmas. Journal of Petrology, 35: 525-541.

Almeida, F.F.M., Leonardos, O.H. \& Valença, J. 1967. Review on granitic rocks of Northeast South America. In: PROCEEDINGS OF THE SYMPOSIUM ON NORTHEASTERN SOUTH AMERICA GRANITES, Recife, IUGS/UNESCO, p. 41

Almeida, F.F.M., Hasuy, H., Brito Neves, B.B. \& Fuck, R.A. 1977. Províncias Estruturais Brasileiras. In: SIMPÓSIO DE GEOLOGIA DO NORDESTE, 8., 1977, Campina Grande. Atas..., SBG, 1977, p. 363-391.

Anderson, J.L. \& Smith, D.R. 1995. The effects of temperature and $\mathrm{fO} 2$ on the $\mathrm{Al}$-in-hornblende barometer. American Mineralogist, 80: 549-559.

Bailey, S.W. 1980. Summary of recommendations of the AIPEA Nomenclature Committee. American Minetralogist, 65: 1-7.

Blundy, J. \& Holland, T. 1990. Calcic amphibole equilibria and a new amphibole-plagioclase geothermometer. Contributions to Mineralogy and Petrology, 104: 208-224.

Brito Neves, B.B. 1995. Crátons e faixas móveis. Boletim de Geociências da USP, 1: 1-187.

Brito Neves, B.B., Van Schmus, W.R., Santos, E.J., Campos Neto, M.C. \& Kozuch, M. 1995. O Evento Cariris Velhos na Província Borborema: integração de dados, implicações e perspectiva. Revista Brasileira de Geo- 
ciências, 25: 279-296.

Buddington, A.F. \& Lindsley, H.D. 1964. Iron-Titanium oxides minerals and synthetic equivalents. Journal of Petrology, 5(2): 310-357.

Czamanske, G.K. \& Wones, D.R. 1973. Oxidation during magmatic differentiation: Finnmarka Complex, Oslo Area, Norway. The mafic silicates. Journal of Petrology, 14: 349-380

Dantas, E.L., Hackspacher, P.C., Van Schmus, W.R. \& Brito Neves, B.B. 1998. Archean accretion in the São José do Campestre Massif, Borborema Province, Northeast Brazil. Revista Brasileira de Geociências, 28: 221-228.

Deer, W.A., Howie, R.A. \& Zussman, J. 1992. An introduction to the rock-forming minerals. 2. ed., Harlow, Longman, 696p.

Enami, M., Suzuki, K., Liou, J.G. \& Bird, D.K. 1993. Al-Fe ${ }^{3+}$ and $\mathrm{F}-\mathrm{OH}$ substitutions in titanite and constraints on their P-T dependence. European Journal of Mineralogy, 5: 219-231.

Evensen, N.M., Hamilton, P.J. \& O’Nions, R.K. 1978. Rare-earth abundances in chondritic meteorites. Geochimica et Cosmochimica Acta, 42: 1199-1212.

Ferreira, V.P., Sial, A.N. \& Jardim de Sá, E.F. 1998. Geochemical and Isotopic Signatures of Proterozoic Granitoids in Terranes of the Borborema Structural Province, Northeast Brazil. Journal of South American Earth Sciences, 11(5): 439-455.

Gill, J.B. 1981. Orogenic Andesites and Plate Tectonics. Berlin, Springer-Verlag, 392p

Guimarães, I.P. \& Bittar, S.M.B. 2011. Mapa Geológico Folha Guarabira SB.25-Y-A-V. Escala 1:100.000 - Serviço Geológico do Brasil - CPRM.

Guimarães, I.P. \& Da Silva Filho, A.F. 1998. Nd- and Sr-isotopic and $\mathrm{U}-\mathrm{Pb}$ geochronologic constraints for the evolution of the shoshonitic Brasiliano Bom Jardim and Toritama complexes: evidence for a Transamazonian enriched mantle under Borborema tectonic province, Brazil. Geology Review, 40: 500-527.

Guimarães, I.P., Da Silva Filho, A.F., Almeida, C.N., Melo, E.B., Araújo, J.M.M. \& Sales, A. 1998. Sm-Nd isotope geochemistry and $\mathrm{U} / \mathrm{Pb}$ zircon ages of the Brasiliano granitoids from the Pajeú-Paraíba Terrain, Borborema Province, Northeastern Brazil. In: SOUTH AMERICAN SYMPOSIUM ON ISOTOPE GEOLOGY, 2., 1998, Córdoba. Anais..., p. 300-301.

Guimarães, I.P., Da Silva Filho, A.F., Almeida, C.N., Van Schmus, W.R., Araújo, J.M.M., Melo, S.C. \& Melo, E.B. 2004. Brasiliano (Pan-African) granite magmatism in the Pajeu-Paraıba belt, Northeast Brazil: An isotopic and geochronological approach. Precambrian Research, 135(1-2): 23-53.

Guimarães, I.P., Bittar, S.M.B. \& Da Silva, J.M.R. 2008. Mapa Geológico - Folha Solânea SB.25-Y-A-IV. Escala 1:100.000 - Serviço Geológico do Brasil - CPRM

Hackspacher, P.C., Santos, T.J.S. \& Lafon, J.M. 1991. Evolução geocronológica do complexo gnaissico-migmatítico do NW Ceara. In: SIMPÓSIO DE GEOLOGIA DO NORDESTE, XIV., Recife. Anais...., Recife, p. 268-271.

Hammarstrom, J.M. \& Zen, E. 1986. Aluminum in hornblende: An empirical igneous geobarometer. Ameri- can Mineralogist, 71: 1297-1313.

Hollister, L.S., Grisson, G., Peters, E.K., Stowell, H.E. \& Sisson, V.B. 1987. Confirmations of empirical correlation of $\mathrm{Al}$ in hornblend pressure of solidification of calc-alkaline plutons. American Mineralogist, 72: 231-239.

Ishihara, S. 1998. Granitoid Series and Mineralization in the Circum-Pacific Phanerozoic Granitic Belts. Resource Geology, 48(4): 219-224.

Johnson, M.C. \& Rutherford, M.J. 1989. Experimental calibration of the aluminium in hornblende geobarometer with application to Long valley Caldera, California volcanic rocks. Geology, 17: 837-841.

Jowett, E.C. 1991. Fitting iron and magnesium into the hydrothermal chlorite geothermometer. GAC/MAC/ SEG Joint Annual Meeting, 1991, Toronto. Program with Abstracts 16, A62. Toronto, p. 27-29.

King, P.L., White, A.J.R., Chappell, B.W. \& Allen, C. M. 1997. Characterization and origin of aluminous A-type granites from the Lachlan Fold Belt, Southeastern Australia. Journal of Petrology, 38: 371-391.

Kruhl, J.H. 1996. Prism- and basal-plane parallel subgrain boundaries in quartz: a microstructural geothermobarometer. Journal of Metamorphic Geology, 14(5): 581 - 589

Lameyre, J. \& Bowden, P. 1982. Plutonic rock type series: discrimination of various granitoids series and related rocks. Journal of Volcanology and Geotermal Research, 14: 169-186.

Leake, B.E., Woolley, A.R., Arps, C.E.S., Birch, W.D., Gilbert, M.C., Grice, J.D., Hawthorne, C. \& Kato, A. 1997. Nomenclature of amphiboles: Report of the subcommittee on amphiboles of the International Mineralogical Association, Commission on new minerals and mineral names. American Mineralogist, 82: 1019-1037.

Lima, J.V., Guimarães, I.P. \& Santos, L. 2015a. Caracterização geoquímica do Plúton Pilõezinhos, Província Borborema, NE Brasil. In: CONGRESSO BRASILEIRO DE GEOQUÍMICA, 15., 2015, Brasília. Anais..., SBGq.

Lima, J.V., Guimarães, I.P., Santos L., Farias, D.J. \& Victor, J. 2015b. Química mineral e condições de cristalização dos granitos tipo-A $\mathrm{A}_{2}$ intrudidos na Zona de Cisalhamento Remígio-Pocinhos / Província Borborema: Plúton Pilõezinhos. In: SIMPÓSIO DE GEOLOGIA DO NORDESTE, 26., 2015, Natal. Palestras e Resumos, SBG, p. 137.

Loiselle, M.C. \& Wones, D.R. 1979. Characteristics and origin of anorogenic granites. Geological Society of America Abstracts, 11: 468.

Nachit, H., Razafimahefa, N., Stussi, J.M. \& Carron, J.P. 1985. Composition chimique des biotites et typologie magmatique des granitos. Comptes Rendus de l'Académie des sciences Paris, 301: 810-818.

Nachit, H., Ibhi, A., Abia, E.H. \& Ohoud, M.B. 2005. Discrimination between primary magmatic biotites, reequilibrated and neoformed biotites. Comptes Rendus Geoscience, 337: 1415-1420.

Neves, S.P. \& Mariano, G. 1999. Assessing the tectonic significance of a large- Scale transcurrent shear zone system: the Pernambuco lineament, northeastern 
Brazil. Journal of Structural Geology, 21: 1369 - 1383.

Neves, S.P., Vauchez, A. \& Feraud, G. 2000. Tectono-thermal evolution, magma emplacement, and shear zone development in the Caruaru area (Borborema Province, NE Brazil). Precambrian Research, 99: 1 32.

Neves, S.P., Bruguier, O., Vauchez, A., Bosch, D., Silva, J.M.R. \& Mariano, G. 2006. Timing of crust formation, deposition of supracrustal sequences, and Transamazonian and Brasiliano metamorphism in the East Pernambuco belt (Borborema Province, NE Brazil): implications for western Gondwana assembly. Precambrian Research, 149:197-216.

Schmidt, M.W. 1992. Amphibole composition in tonalite as a function of pressure: An experimental calibration of the Al-in-hornblende-barometer. Contributions to Mineralogy and Petrology, 110: 304-310.

Sial, A.N. 1986. Granites -Type in Northeast Brazil: Current Knowledge. Revista Brasileira de Geociências, 16(1): $54-72$.

Silva, J.M.R. \& Mariano, G. 2000. Geometry and kinematics of the Afogados da Ingazeira shear zone, northeast Brazil. International Geology Review, 42: 86 - 95.

Silva Filho, A.F., Guimarães, I.P., Van Schmus, W.R., Dantas, E., Armstrong, R., Concentino, L. \& Lima, D. 2013. Long-lived Neoproterozoic high-K magmatism in the Pernambuco-Alagoas Domain, Borborema Province, northeast Brazil. International Geology Review, 55 (10): 1280-1299.

Streckeisen, A.L. 1976. Classification and nomenclature of igneous rocks: Earth-Science Reviews, 12: 1-35.

Thomas, W.M., \& Ernst, W.G. 1990. The aluminum content of hornblende in calc-alkaline granitic rocks: A mineralogic barometer calibrated experimentally to 12 kbars. Fluid-mineral interactions: A tribute to $H$. P. Eugster. Geochemical Society Special Publication, 2: 59-63.

Tulloch, A.J. 1979. Secondary Ca-Al silicates as lowgrade alteration products of granitoid biotite. Con- tribution to Mineralogy and Petrology, 69: 105-117. Van Schmus, W.R., Brito Neves, B.B., Hachspacher, P. \& Babinski, M. 1995. U/Pb and Sm/Nd geochronolgic studies of eastern Borborema Province, northeastern Brazil, initial conclusions. Jounal of South American Earth Sciences, 8: 267 - 288.

Van Schmus, W.R., Oliveira, E.P., Silva Filho, A.F., Toteu, S.F., Penaye, J. \& Guimarães, I.P. 2008. Proterozoic Society of London, Special Publication, 294: 69 - 99.

Vauchez, A. \& Egydio-Silva, M. 1992. Termination of a continental-scale strike-slip fault in partially melted crust: The West-Pernambuco Shear Zone, northeast Brazil. Geology, 20: 1007 - 1010.

Vernon, R.H. 1991. Questions about myrmekite in deformed rocks. Journal of Strutural Geology, 2: 979 985.

Watson, E.B. 1979. Zircon saturation in felsic liquids: experimental results and application to trace element geochemistry. Contributions to Mineralogy and Petrology, 70: 407-419.

Watson, E.B. 1987. The hole of accessory minerals in granitoids geochemistry. In: HUTTON CONFERENCE OF THE ORIGIN OF GRANITES, 4., 1987, Edinburgh. Anais..., p. 209-211.

Watson, E.B. \& Harrison, T.M. 1983. Zircon saturation revisited: temperature and composition effects in a variety of crustal magma types. Earth and Planetary Science Letters, 64: 295 - 304.

Watson, E.B. \& Harrison, T.M. 1984. Accessory phases and the geochemical evolution of crustal magmas. Physics of the Earth and Planetary Interiors, 35: 19 - 30.

Wones, D.R. 1989. Significance of the assemblage titanite + magnetite + quartz in Granitic rocks. American Mineralogist, 74: 744-749.

Williams, C.T. 1996. Analysis of rare earth minerals. In: Jones, A.P., Wall, F., Williams, C.T (Ed.). Rare Earth Minerals: Chemistry, Origin and Ore Deposits. London, Chapman and Hall, p. 327-348.
Manuscrito 599

Editor: Lauro V. S. Nardi \& Paulo A. Souza 
